\title{
CICLOESTRATIGRAFIA DA SEQÜÊNCIA CARBONÁTICO-EVAPORÍTICA PENSILVANIANA DA BACIA DO SOLIMÕES, NORTE DO BRASIL
}

\author{
CARLOS ROBERTO BECKER
}

\begin{abstract}
CYCLOSTRATIGRAPHY OF THE PENNSYLVANIAN CARBONATE-EVAPORITIC SEQUENCE OF THE SOLIMOOES BASIN, NORTHERN BRAZIL - This paper presents the results of cyclostratigraphic analysis in a carbonate-evaporitic succession of Pennsylvanian age in the Solimões Basin, northern Brazil. An integrated approach of several techniques and tools was applied in order to identify the main allocyclic controls that governed the deposition of the carbonates and evaporites and to build a high resolution chronostratigraphic framework.

The stratigraphic analysis based on the sedimentary stacking patterns recognized in the gamma ray and sonic logs made it possible to individualize eight depositional composite sequences of $3 \mathrm{rd}$ order, which can be subdivided in cyclical sequence sets of 4 th and 5 th orders.

The deposition of $3 \mathrm{rd}$ order sequences is due to the regional subsidence of the basin and, in some cases, can be related to tectonic uplifts at the borders of the basin, and in the areas of the Carauari Arch and Jandiatuba Sub-basin. This tectonic activity was interpreted as a consequence of the intercontinental collision between Gondwana and Laurussia in the end of the Carboniferous, called herein as Jandiatuba Tectonic Event. This event was contemporary to the formation of the Ouachita-Marathon orogenic belt, in the southwestern USA, and was coeval with the great subsidence in some of the American Midcontinent basins, such as the Paradox Basin.

The cyclostratigraphic analysis of the 4th and 5th order cyclic sequences revealed that associations of some thicknesses showed relationships that could be related to orbital cycles of short eccentricity and precession.

Therefore, it was concluded that the main allocyclic control which governed the construction of the 4th and 5th order cyclic sequences was the glacio-eustasy driven by orbital forcing in the Milankovitch bandwidth of frequencies. This finding indicates that it is possible to establish intercontinental correlation between carbonate-evaporitic sections of the Solimões Basin and other contemporary cyclic successions worldwide, particularly with the North American Midcontinent cyclothems of Pennsylvanian age.
\end{abstract}

\begin{abstract}
Resumo Este trabalho apresenta os resultados de análises de ciclicidade feitos em uma sucessão carbonática-evaporítica pensilvaniana da Bacia do Solimões, no norte do Brasil. Foi usada uma abordagem integrada de diversas técnicas e ferramentas para identificar os principais controles deposicionais alocíclicos e para construir um arcabouço cronoestratigráfico de alta resolução. A análise estratigráfica baseada nos padrões de empilhamento sedimentar nos perfis de raios gama e sônicos possibilitou identificar oito seqüências deposicionais compostas de $3^{\mathrm{a}}$ Ordem que, por sua vez, podem ser divididas em conjuntos cíclicos de $4^{\mathrm{a}}$ e $5^{\mathrm{a}}$ ordens.

As sequâencias de $3^{\text {a }}$ Ordem estão associadas à subsidência e, em alguns casos particulares, a soerguimentos nas bordas da bacia $\mathrm{e}$ na área do Arco de Carauari e Sub-bacia do Jandiatuba. Essa atividade tectônica foi interpretada como a conseqüência da colisão intercontinental entre o Gondwana e a Laurússia no final do Carboniffero, chamada aqui de Evento Tectônico Jandiatuba. Este evento foi contemporâneo à formação do Orógeno Ouachita-Marathon no sudoeste dos EUA e a eventos de forte subsidência em bacias interiores norte-americanas, como a Bacia de Paradox.

As análises cicloestratigráficas dos ciclos de $4^{\mathrm{a}} \mathrm{e} 5^{\mathrm{a}}$ ordens indicaram associações de determinadas frequiências de espessuras, cujas relações mútuas apontam para atuação de ciclos de excentricidade curta e precessão. Conclui-se assim que o principal controle alocíclico que modelou a construção desses ciclos foi a glácio-eustasia induzida por forçamento orbital de Milankovitch. Essa constatação aponta para amplas possibilidades de correlação entre os ciclos carbonático-evaporíticos e os ciclotemas do Pensilvaniano norte-americano.
\end{abstract}

\begin{abstract}
INTRODUÇÃO
O sub-período Pensilvaniano (Carbonífero Superior) é bastante conhecido pela notável ciclicidade dos depósitos sedimentares, tanto em clima úmido (ciclotemas norte-americanos do Midcontinent) quanto seco (ciclos evaporíticos da Bacia de Paradox, Utah, EUA). A deposição das seções cíclicas norte-americanas foi influenciada por variações eustáticas relacionadas ao avanço e retração das geleiras que recobriam a maior parte do paleocontinente Gondwana (Crowell, 1978; Caputo \& Crowell, 1985; Veevers \& Powell, 1987).

Os registros sedimentares dessa glácio-eustasia sobre a maior parte do Gondwana são escassos e insuficientes para reconstituir com detalhes as variações eustáticas, pois muito desses registros estão ausentes por erosão ou não deposição.

Afortunadamente, as Bacias do Solimões e do Amazonas foram sítios de deposição de espessas seções de carbonatos e evaporitos a partir de transgressões marinhas provindas principalmente do Oceano Pacífico a oeste, especialmente na Bacia do Solimões.
\end{abstract}

Altiner \& Savini (1991) identificaram e caracterizaram nessas bacias uma associação faunística de fusulinídeos extremamente semelhante a que ocorre no Carbonífero norte-americano, abrindo uma espetacular possibilidade de correlação da seção carbonático-evaporítica com as seções norte-americanas. Esse zoneamento bioestratigráfico veio a se somar ao que foi proposto por Lemos (1990), baseado em conodontes.

Os trabalhos de Silva (1996) na Bacia do Amazonas e de Becker (1997) na Bacia do Solimões estabeleceram propostas de arcabouço estratigráfico baseadas em conceitos eștratigráfi$\cos$ modernos, integrando todas as informações bioestratigráficas, cronoestratigráficas e isotópicas existentes nas duas bacias.

Sob essa visão de integração de dados, o presente trabalho irá mostrar a aplicação da análise cicloestratigráfica à seção pensilvaniana, caracterizando a notável ciclicidade e mostrando sua importante contribuição ao entendimento dos fatores que governaram a deposição sedimentar e a criação de espaço deposicional na bacia. 


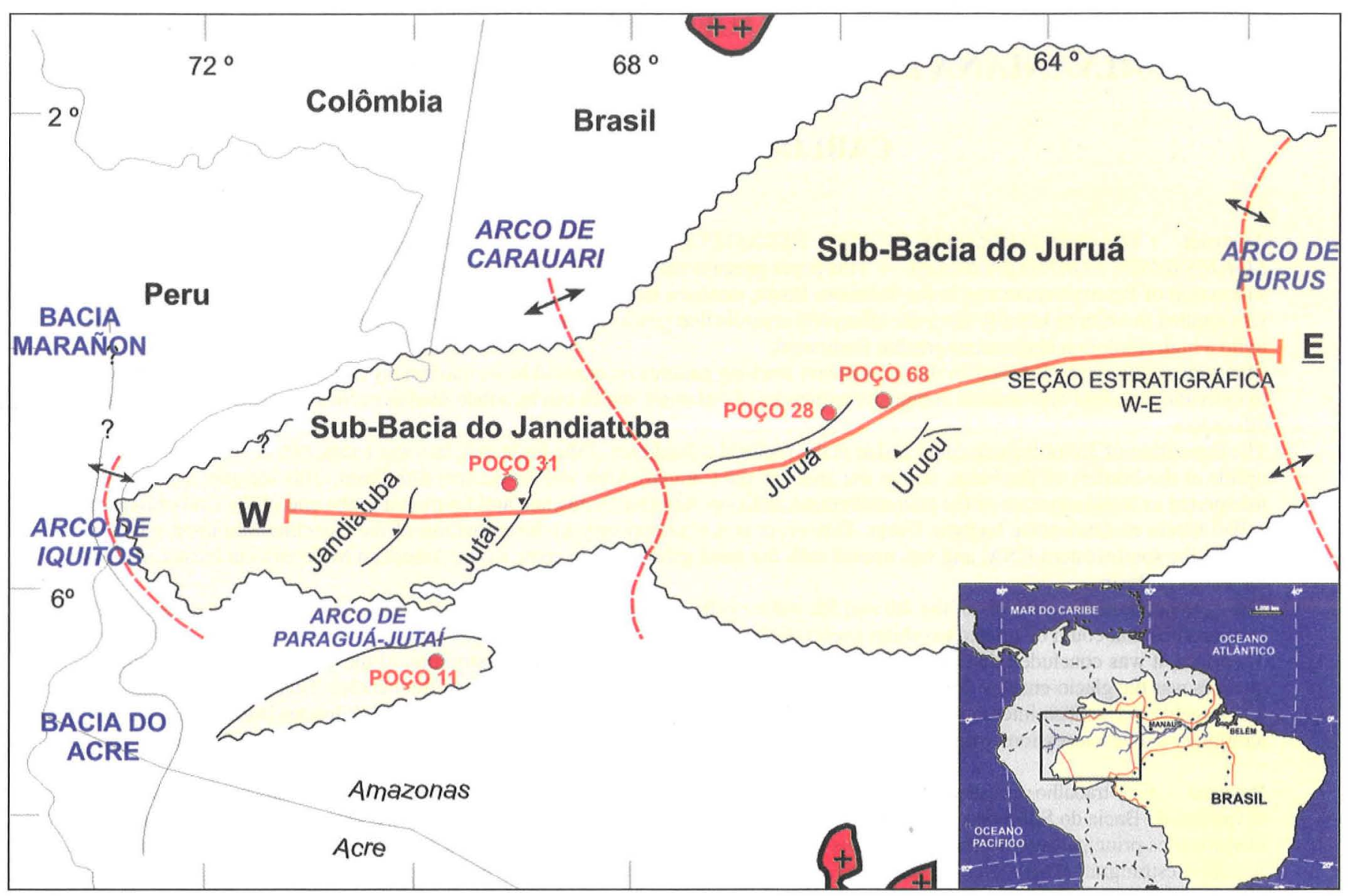

Figura 1: Mapa de localização da Bacia do Solimões, com indicação da seção estratigráfica regional e dos poços citados no texto.

Geologia Regional A Bacia do Solimões é uma bacia paleozóica intracratônica, não aflorante, situada na região norte do Brasil (figura 1), limitada a norte pelo Escudo das Guianas, a sul pelo Escudo Brasileiro, e separada das Bacias do Acre e Marañon a oeste, pelo Arco de Iquitos, e da Bacia do Amazonas a leste, pelo Arco de Purus.

Aseção paleozóica compreende rochas cujas idades variam do Ordoviciano até o Permiano. As grandes seqüências estratigráficas da bacia foram definidas com a revisão litoestratigráfica feita por Eiras et alii (1994). Existem duas seqüências de $1^{\text {a }}$ Ordem, Paleozóica e Mesozóica/Cenozóica. A Seqüência Paleozóica é composta por quatro seqüências de $2^{\text {a }}$ Ordem (Ordoviciana, Siluro-Devoniana, Devoniana-Carbonífera e Permo-Carbonífera) e a Seqüência Mesozóica/Cenozóica por duas seqüências de $2^{\text {a }}$ Ordem (Cretácea e Terciária).

Nessa carta litoestratigráfica a Seqüência Permo-Carbonífera corresponde ao Grupo Tefé, que abrange as formações Juruá, Carauari e Fonte Boa. Predominam amplamente as intercalações cíclicas de rochas evaporíticas e carbonáticas da Formação Carauari, com eventual aporte de siliciclásticos representados na base pela Formação Juruá e no topo pelos red beds da Formação Fonte Boa.

Szatmari et alii $(1975,1979)$ propuseram o primeiro arcabouço cicloestratigráfico para a seção carbonático-evaporítica Pensilvaniana. Dividiram a seção em 11 ciclos limitados no topo e base por folhelhos, geralmente os principais marcos estratigráficos das bacias do Amazonas e Solimões.

Fato digno de nota é a ocorrência regional de intrusões de soleiras de diabásio, de idade Juro-Triássica, que entram preferencialmente ao longo do contato entre camadas de halita e folhelho. Localmente podem subdividir-se em corpos menores e apófises, mas em geral ocorrem 3 ou 4 soleiras na Sub-bacia de Jandiatuba e na porção oeste da Sub-bacia do Juruá, e 2 soleiras na porção leste até o Arco de Purus. As espessuras das soleiras são da ordem de 300 a 500 metros. Não existem evidências de assimilação de sedimentos ou de evaporitos em larga escala pelas soleiras.

Base de Dados Foram usados 82 perfis compostos, em escala 1:1.000, de poços pioneiros com suas respectivas curvas de perfis de raios gama, de tempo de trânsito sônico e resistividade, 450 seções delgadas, e testemunhos obtidos em poços situados em várias posições na bacia.

Nos estudos isotópicos de $\delta^{18} \mathrm{O}$ e $\delta^{13} \mathrm{O}$ foram usadas 63 amostras de calha ao longo do poço $n^{\circ} 31$, no Arco de Carauari. Para cada amostra foi confeccionada uma seção delgada, usada para análises petrográficas e bioestratigráficas. Foram coletadas e analisadas 21 amostras de anidritas para construir uma curva da razão ${ }^{87} \mathrm{Sr} /{ }^{86} \mathrm{Sr}$ no poço n ${ }^{0} 68$, no centro da Sub-bacia do Juruá (localização na figura 1).

A fundamentação do modelo de idade foi suportada pelos estudos disponíveis, faciológicos e bioestratigráficos usandose, também, 133 fichas de leitura micropetrográfica feitas por Demir Altiner em 1991, cujas informações não haviam sido publicadas. Foi adotado o zoneamento bioestratigráfico por fusulinídeos proposto por Silva (1996) em sua tese de doutorado sobre o Pensilvaniano da Bacia do Amazonas.

HIPÓTESE E MÉTODOS DE TRABALHO A principal hipótese testada neste estudo é verificar a possibilidade de que a ciclicidade dos carbonatos e evaporitos pensilvanianos foi causada por glácio-eustasia, induzida por forçamento orbital de 


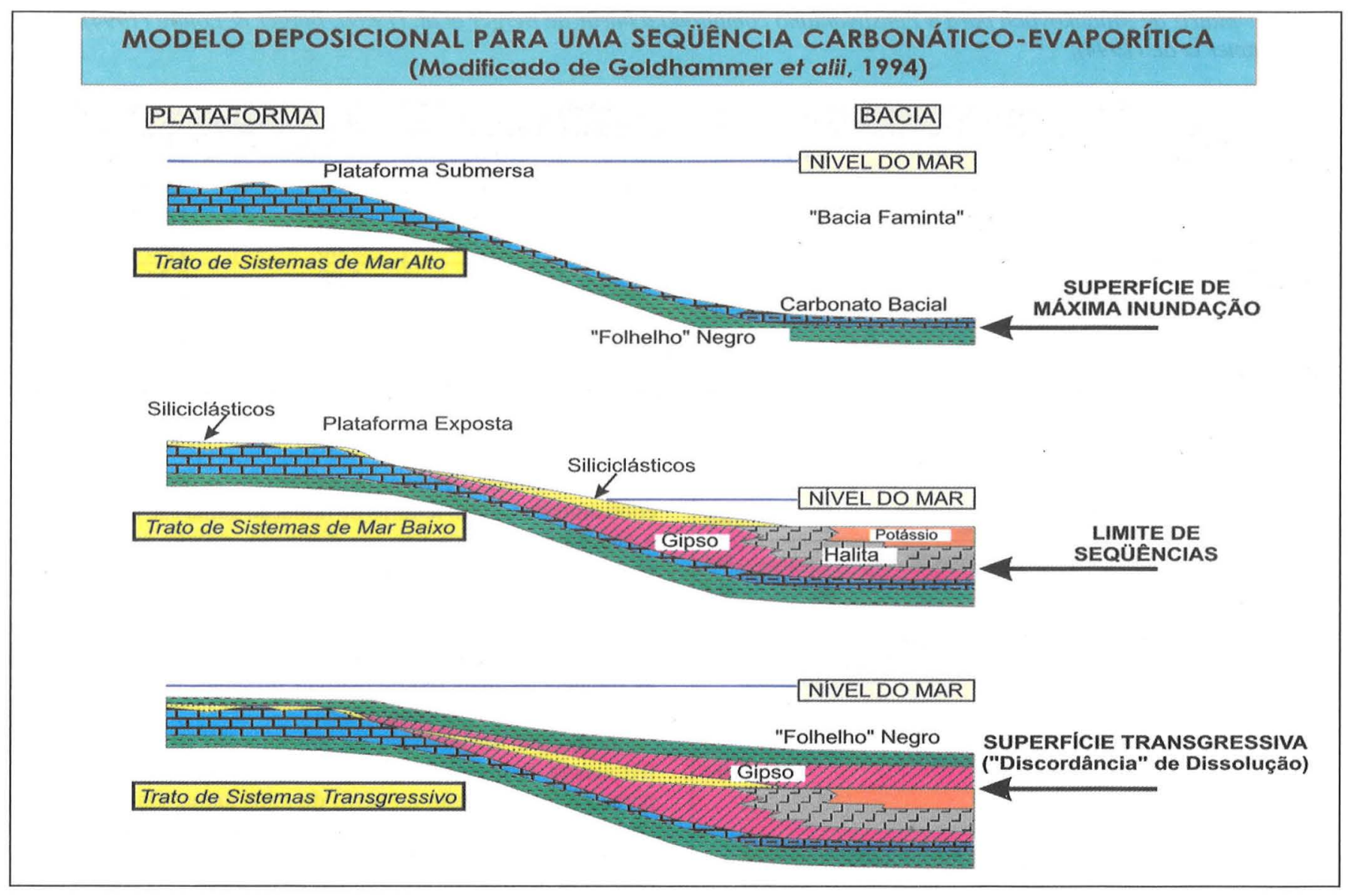

Figura 2: Desenvolvimento dos tratos de sistemas de uma seqüência carbonático-evaporítica ideal. Os sais constituem os depósitos de mar baixo, estando sobre um limite de seqüencia concordante, ou conformidade correlativa (editado de Goldhammer et al., 1994).

Milankovitch.

Premissas Os conceitos estratigráficos de seqüência aqui utilizados basearam-se nos trabalhos de Tucker (1991), Mitchum \& Van Wagoner (1991), Goldhammer et al. (1994) e Youle et al. (1994). Está também implícita a idéia de que a seqüência deposicional não depende de tempo e espaço (Posamentier \& James, 1993), mantendo sua identidade em várias escalas de observação.

De acordo com esses conceitos (Goldhammer et al., 1994), os depósitos de evaporitos, em especial halita, são considerados como pertencentes ao Trato de Sistemas de Mar Baixo que por definição se assenta sobre uma discordância Tipo I ou sua concordância correlata (figura 2).

No presente estudo, a análise cicloestratigráfica foi refinada pela integração de um grande volume de dados originados por diversas ferramentas, destacando-se a bioestratigrafia (fusulinídeos) e a cronoestratigrafia isotópica (estudos da razão $\left.{ }^{87} \mathrm{Sr} /{ }^{86} \mathrm{Sr}\right)$.

Padrões de Empilhamento Sedimentar A ferramenta principal para essa análise é o perfil de raios gama, associado às litologias interpretadas que foram perfuradas, e aos perfis sônico, de resistividade e de densidade. Os perfis foram editados, excluindo-se os intervalos com soleiras de diabásio, sob a premissa de que o diabásio não assimila as rochas encaixantes, nem influencia regionalmente a distribuição e espessura das camadas.

A seção foi subdividida no perfil de raios gama do poço $\mathrm{n}^{\circ}$ 68 , onde a seção está mais completa. Foram reconhecidos os diferentes padrões de freqüência da curva e de variação de es-

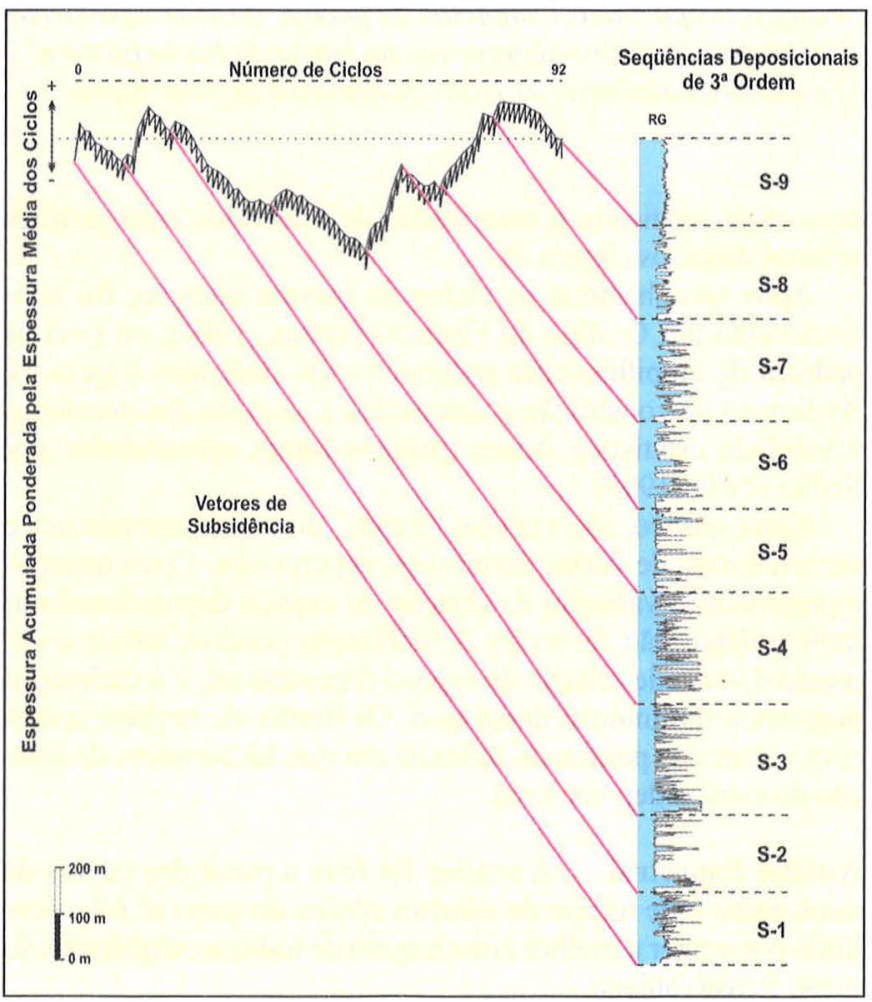

Figura 3: Subdivisão em seqüências de $3^{a}$ Ordem baseada nos padrões de empilhamento sedimentar cíclicos, realçados pelo respectivo Gráfico de Fischer à esquerda. 
Tabela 1: Matriz de Milankovitch para o Pensilvaniano compilada a partir de Berger et al. (1989), Berger \& Loutre (1994) e Goldhammer et al. (1994).

\begin{tabular}{|c|c|c|c|c|c|c|c|}
\hline \multirow[b]{2}{*}{ Duração } & \multicolumn{2}{|c|}{ PRECESSÃO } & \multicolumn{2}{|c|}{ OBLIQÜIDADE } & \multicolumn{2}{|c|}{ EXCENTRIC. CURTA } & \multirow{2}{*}{$\begin{array}{l}\text { EXC. LN. } \\
400.000\end{array}$} \\
\hline & 17.387 & 20.678 & 34.163 & 42.736 & 95.000 & 123.000 & \\
\hline 17.387 & 1 & 1,19 & 1,96 & 2,50 & 5,46 & 7,07 & 23,00 \\
\hline 20.678 & & 1 & 1,65 & 2,10 & 4,59 & 5,95 & 19,34 \\
\hline 34.163 & & & 1 & 1,30 & 2,78 & 3,60 & 11,71 \\
\hline 42.736 & & & & 1 & 2,22 & 2,88 & 9,36 \\
\hline 95.000 & & & & & 1 & 1,29 & 4,21 \\
\hline 123.000 & & & & & & 1 & 3,25 \\
\hline 400.000 & & & & & & & 1 \\
\hline
\end{tabular}

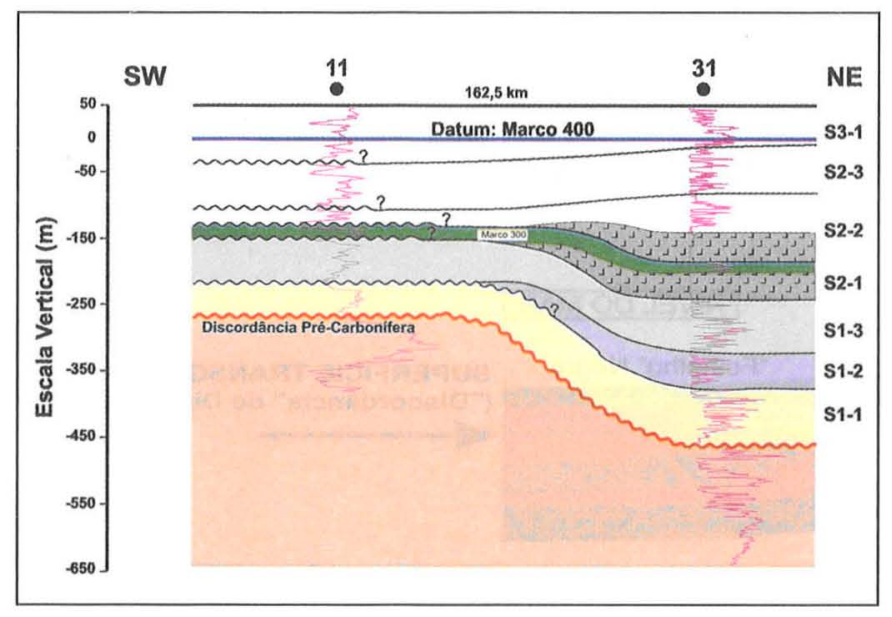

Figura 4: Seção estratigráfica ilustrando o padrão estratigráfico das seqüências evaporiticas de $4^{a}$ Ordem. A curva ilustrada em cada poço é o perfil de raios gama. Notar que as seqüencias evaporiticas completas do poço $n^{\circ} 31$ corresponderão a ciclos transgressivo-regressivos na borda da bacia (poço $n^{o}$ 11), devido à ausência do Trato de Sistemas de Mar Baixo.

pessura, e verificada a recorrência de intervalos com padrões cíclicos distintos (figura 3 ).

Após reconhecidos os ciclos de mesma duração, foi confeccionado um Gráfico de Fischer (Fischer, 1964), no qual os padrões de empilhamento sedimentar são realçados (figura 3). As formas de construção e discussões a respeito das premissas e validade estatística desses gráficos foram apresentadas por Sadler et alii (1993).

Neste gráfico, são visíveis "trends" de ondas ascendentes e descendentes, de várias dimensões, superpostos. Esses arranjos representam a variação da criação de espaço deposicional durante a deposição da seção. A inclinação positiva reflete o aumento da taxa de criação de espaço deposicional, e a inclinação negativa a diminuição dessa taxa. Os limites de seqüência correspondem aos pontos de inflexão em que há aumento de criação do espaço deposicional.

Análise Espectral A análise foi feita a partir das curvas de raios gama e de tempo de trânsito sônico do poço $\mathrm{n}^{\circ} 68$, escolhido por conter a melhor amostragem de todas as seqüências da seção Pensilvaniana.

Os intervalos com halita foram eliminados por serem considerados como eventos geologicamente instantâneos devido à alta taxa de precipitação $(5 \mathrm{~cm} / \mathrm{ano}$, de acordo com Hite \& Buckner, 1991) e às altas espessuras, que poderiam introduzir erros nas análises. Como as halitas sempre ocorrem intercaladas entre anidritas, cujas leituras de radiação gama são semelhantes, a análise matemática não faz distinção, exceto com relação à espessura do ciclo, que deve ser analisada através de gráficos de Fischer.

Com o uso de um software de análise estatística, aplicou-se a Análise Espectral de Fourier aos dados, identificando-se assim as freqüências mais representativas presentes em cada seqüência, ilustradas em periodogramas.

A divisão do intervalo de amostragem $(0,2 \mathrm{~m})$ por cada freqüência forneceu um comprimento de onda, que foi comparado à interpretação no perfil de raios gama. Os valores sem correspondência foram descartados, e aqueles presentes no perfil foram colocados em uma matriz, calculando-se as razões mútuas entre os diversos comprimentos de onda.

Nos estudos cicloestratigráficos encontrados na literatura (p.ex.: Goldhammer et al., 1994) a correção para compactação dos sedimentos (backstripping) é sempre feita antes da análise espectral.

Como os resultados que interessam são as relações mútuas entre os ciclos, que serão comparadas àquelas da Matriz de Milankovitch, optou-se por não fazer a descompactação. No caso específico da seção estudada considerou-se que tal erro será maior apenas em freqüências mais altas $\left(5^{\mathrm{a}}\right.$ para $6^{\mathrm{a}}$ ordem), que não foram o objeto do presente estudo.

Usualmente, a comparação das razões é feita com uma matriz de Milankovitch, que relaciona as razões entre os diferentes parâmetros orbitais. Devido à desaceleração do sistema solar ao longo do tempo geológico, as durações dos parâmetros orbitais variaram (Schwarzacher, 1991), indicando que é recomendável fazer a comparação com informações relativas ao período de tempo geológico considerado.

Assim, foi montada uma Matriz de Milankovitch para o Pensilvaniano a partir de uma compilação da literatura, apresentada na tabela ${ }^{\circ} 1$.

Somente foram consideradas válidas as razões com pelo menos $95 \%$ de similaridade àquelas da tabela 1 . No caso de razões semelhantes entre diferentes freqüências, a hipótese mais provável foi escolhida após análise dos perfis de raios gama e sônico, buscando identificar espessuras de ciclos geologicamente compatíveis, e através de taxas de sedimentação.

Identificadas as espessuras de ciclos relacionadas a fatores orbitais, o passo seguinte foi obter a duração de cada seqüência, multiplicando-se a duração do parâmetro orbital (preferencialmente excentricidade curta) pelo número de ciclos identificado na seção (tabela 1).

A duração assim obtida deve ser considerada como uma duração mínima, em função das premissas adotadas, em especial a de que a deposição da sequeência foi contínua, o que na maioria das vezes pode não corresponder à realidade (Anders et al., 


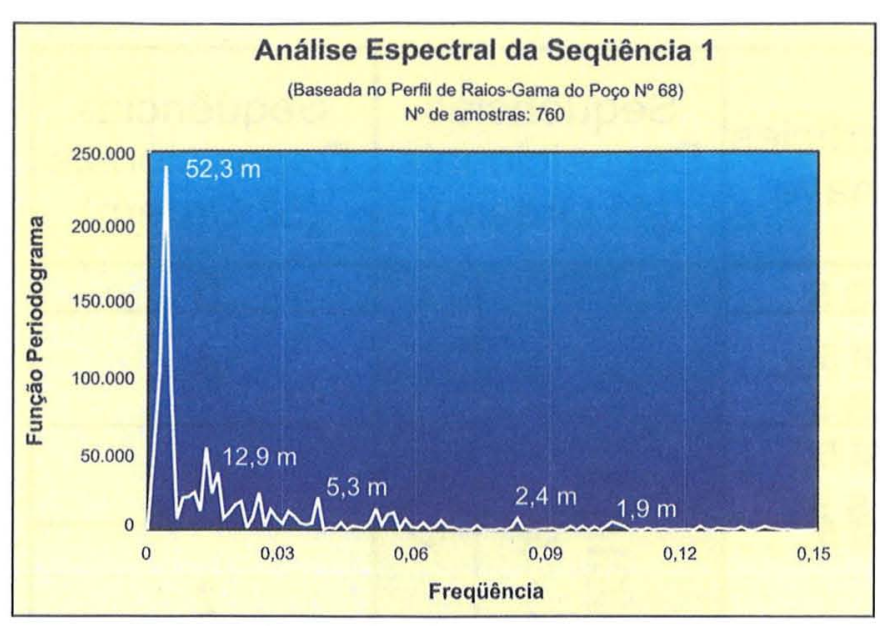

Figura 5: Periodograma da Seqüência S1.

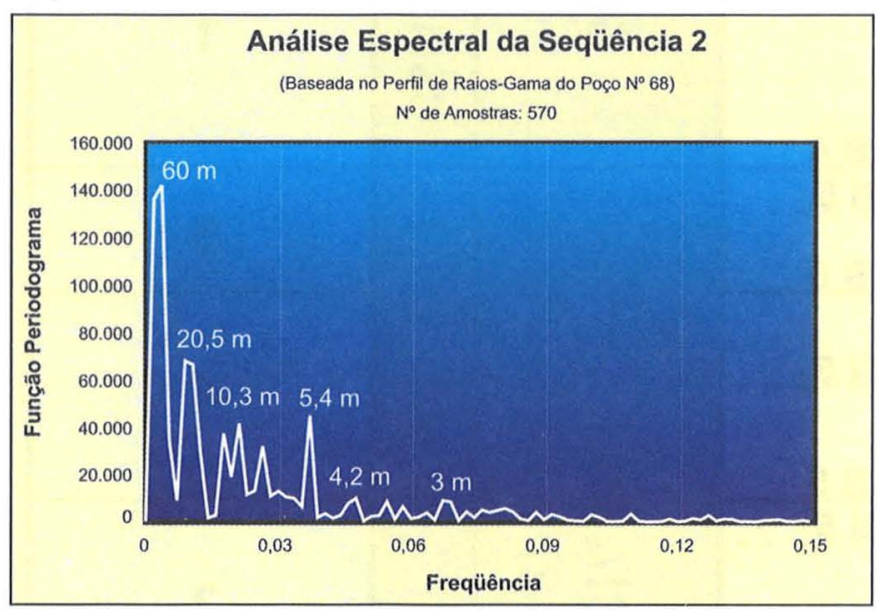

Figura 6: Periodograma da Seqüência S2.

1987). Essa duração é então comparada com aquelas interpretadas a partir das determinações bioestratigráficas, permitindo estimar a duração dos hiatos na seqüência.

Maiores detalhes sobre a metodologia empregada e fundamentos teóricos da análise espectral podem ser obtidos nos trabalhos de Azambuja (1994) e Becker (1997).

ESTRATIGRAFIA DE SEQÜÊNCIAS As características comuns de padrões de empilhamento cíclico permitiram individualizar nove conjuntos distintos. Como esses conjuntos estão inseridos dentro de uma seqüência de $2^{\mathrm{a}}$ Ordem, a Permo-Carbonífera, hierarquicamente correspondem a seqüências de $3^{\mathrm{a}}$ Ordem, nomeadas a partir da base como S1 a S9.

Seqüências de $3^{\text {a }}$ Ordem Estas seqüências, como observado em diversas regiões intracratônicas do Brasil (Soares et al., 1978) e do mundo (Ross \& Ross, 1985, 1988), apresentam um padrão de empilhamento sedimentar transgressivo-regressivo. Os limites entre essas seqüências são definidos através da identificação de mudanças nos padrões de empilhamento sedimentar, e também pela presença de cunhas evaporíticas expressivas. A associação cíclica em diversas ordens de grandeza, a pequena criação de espaço deposicional, e a predominância de fatores locais produzem uma assinatura estratigráfica complexa, cuja hierarquização nos moldes tradicionalmente propostos pela Estratigrafia de Seqüências para as margens continentais é impraticável.

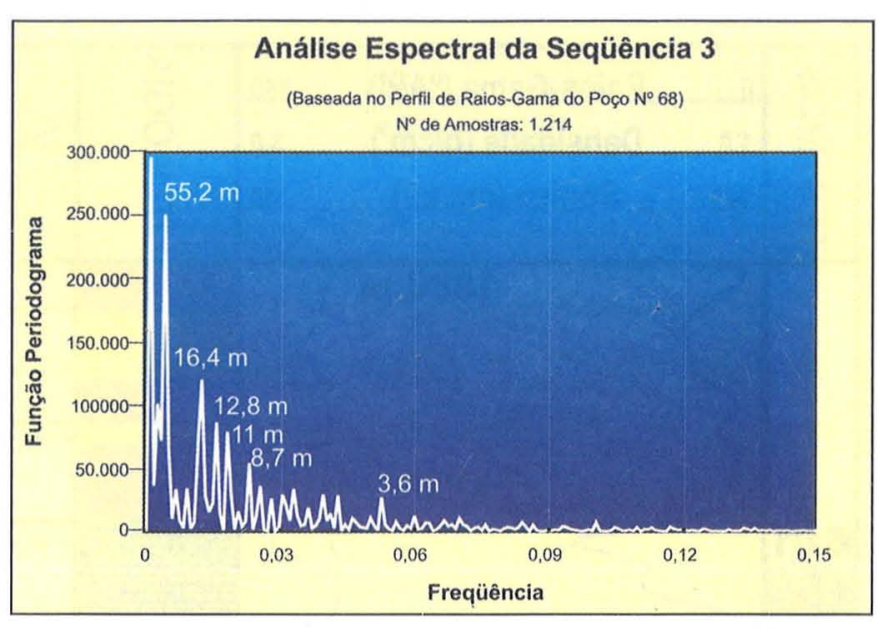

Figura 7: Periodograma da Seqüência S3.

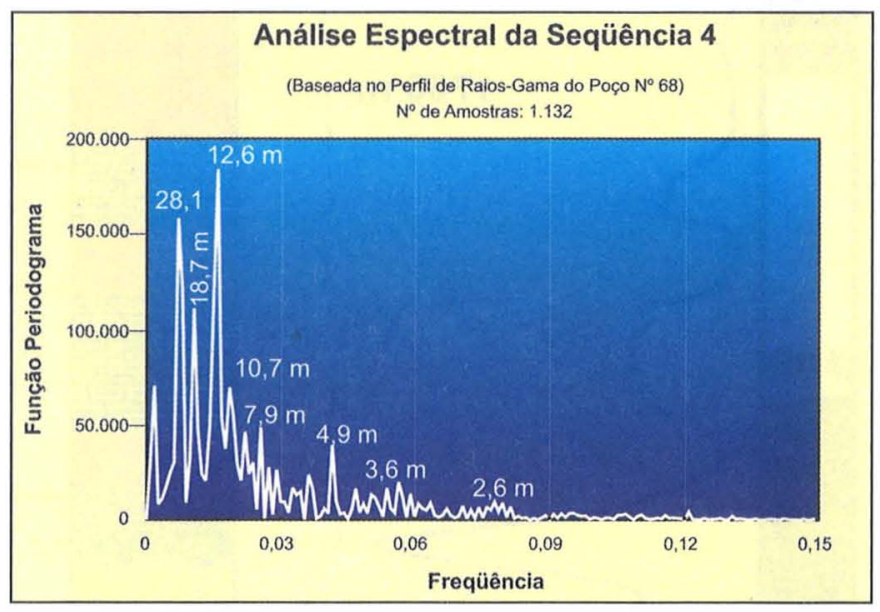

Figura 8: Periodograma da Seqüencia S4.

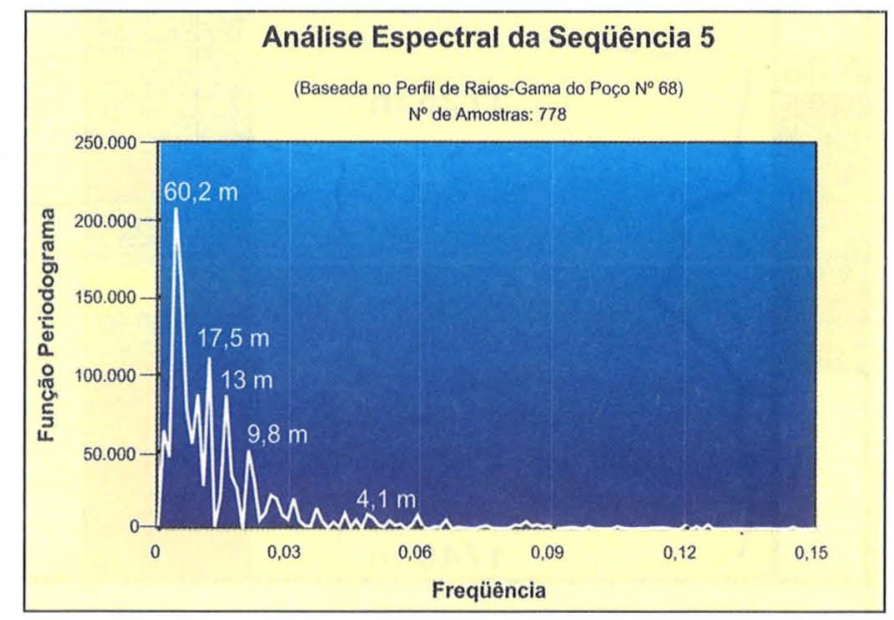

Figura 9: Periodograma da Seqüência S5.

A organização interna das seqüências de $3^{\mathrm{a}}$ Ordem não mostra um padrão claro de divisão em tratos de sistemas. Ao invés disso, apresentam características muito próximas daquilo que Youle et al. (1994) chamaram de composite sequence ou seqüência composta, baseada em uma definição criada por Mitchum \& Van Wagoner (1991). 


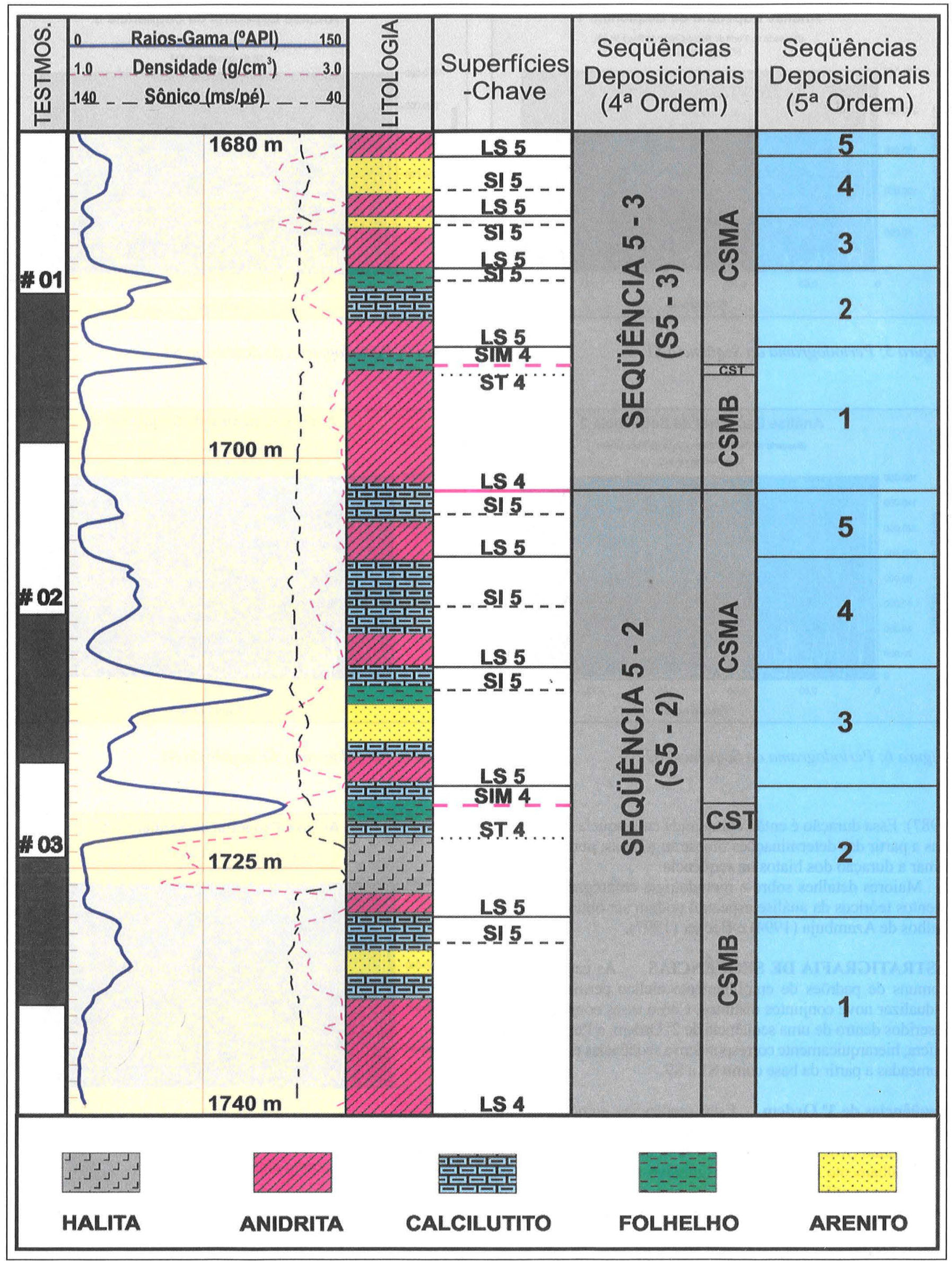

Figura 10: Hierarquização estratigráfica das seqüencias S5-2 e S5-3, baseadas em análises de testemunhos e de perfis elétricos, acústicos e radioativos. Os limites de seqüencias de $4^{a}$ Ordem (LS4) são marcados próximo à base das halitas, ou no topo de anidritas laminadas/maciças. Notar a disposição das seqüências de $5^{a}$ Ordem segundo um padrão de afinamento para o topo (thinning upward). 


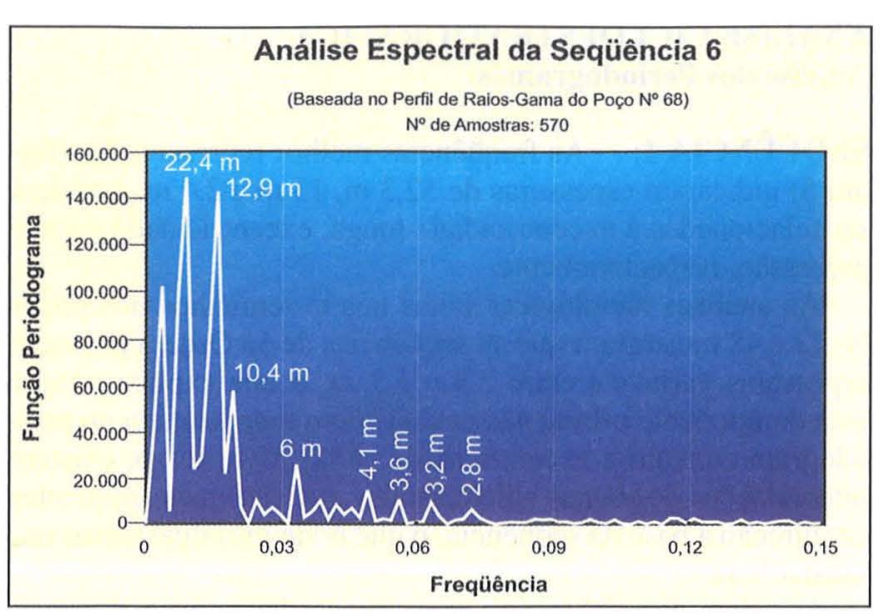

Figura 11: Periodograma da Seqüência S6.

No caso das seqüências de $3^{\mathrm{a}}$ Ordem, elas seriam "compostas" por conjuntos de $4^{\mathrm{a}}$ ordem. Como há diferenciações nos padrões de empilhamento, esses conjuntos serão aqui tratados como seqüências de $4^{\mathrm{a}}$ Ordem. Na estratigrafia composta, os elementos construtores são seqüências de alta freqüência, dentro da $5^{\text {a }}$ Ordem.

Seqüências de $4^{\text {a }}$ Ordem A hierarquização interna das seqüências de $3^{\mathrm{a}}$ Ordem da Seqüência Permo-Carbonífera pode ser feita em três categorias, denominadas de conjunto de seqüências de mar baixo (CSMB), conjunto de seqüências transgressivas (CST) e conjunto de sequiências de mar alto (CSMA).

O CSMB é composto por intercalações cíclicas de $5^{\mathrm{a}}$ Ordem entre halitas, anidritas de sabkha, arenitos eólicos e fluviais, mudstones laminados (laminitos algálicos) e eventualmente folhelhos lacustres. O padrão de empilhamento sedimentar é agradacional a progradacional.

Anidritas situadas logo acima de halitas são consideradas como transgressivas, pois indicam diluição da salmoura e a entrada de sulfato no sistema, atribuída a transgressões marinhas (vide figura 2).

O padrão de empilhamento característico do CST é o retrogradacional, identificável pela radioatividade crescente dos folhelhos e calcilutitos em direção à Superfície de Inundação Máxima (SIM) da seqüência de $3^{\text {a }}$ Ordem.

O limite inferior com o CSMB situa-se em discordâncias de dissolução sobre halitas, superfícies erosivas associadas a clastos arrancados, ou brusco aprofundamento da lâmina d'água, inferido por contrastes litofaciológicos. Nas bordas da bacia, essa superficie transgressiva coincide com o limite de seqüências.

O CSMA apresenta folhelhos pretos carbonosos de offshore, mudstones pretos laminados e com formas de leito onduladas, por vezes com espículas de esponjas, e litofácies heterolíticas, eventualmente perturbadas por escorregamentos e bioturbações.

Predominam padrões de empilhamento progradacionais, exatamente opostos aos observados no CST, com a radioatividade decrescendo na direção do topo das seqüências. Padrões agradacionais também são característicos do CSMA, e foram observados nas seqüências S4-3 e S4-4, e na S7.

A bioturbação tende a se intensificar para o topo, bem como o conteúdo fossilífero. O topo do CSMA é caracterizado por anidritas laminadas, laminitos algálicos e grainstones oolíticos nas áreas de maior energia. Nas áreas de baixa energia ocorrem fácies lagunares ricas em gastrópodos, e presença de nódulos de sal, indicativos de processos de bombeamento evaporativo.

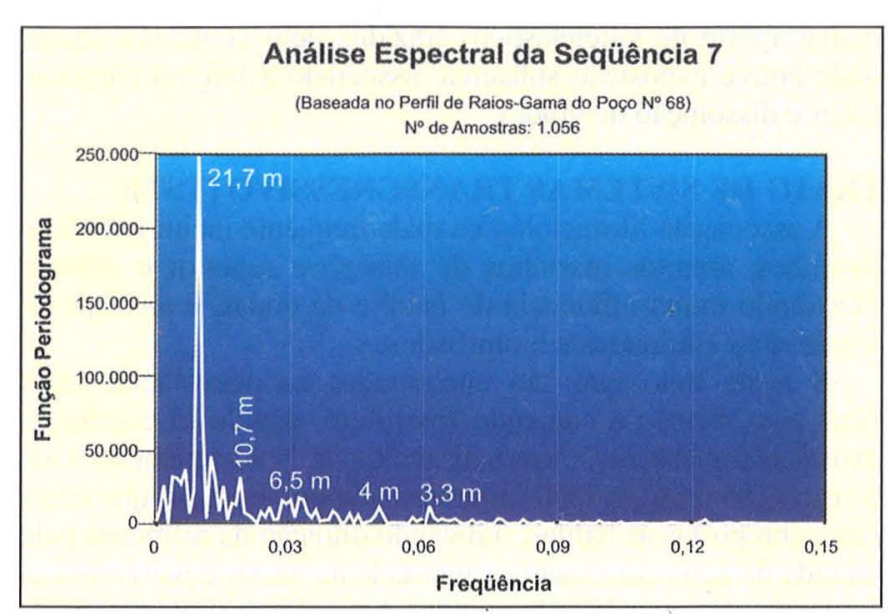

Figura 12: Periodograma da Seqüência S7.

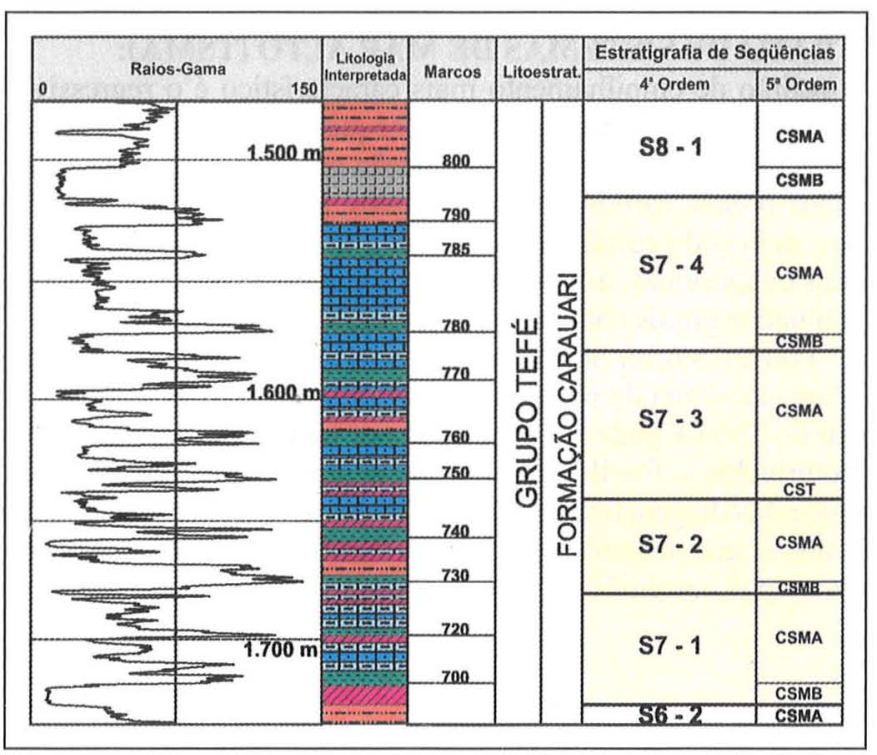

Figura 13: Interpretação geológica da Seqüência 7, ilustrando a notável ciclicidade sedimentar.

Seqüiências de $5^{\text {a }}$ Ordem No cenário de estratigrafia composta, as seqüências de $5^{\text {a }}$ Ordem correspondem às unidades fundamentais do arcabouço estratigráfico, com espessuras médias em geral variando entre 5 e 15 metros. Excepcionalmente podem chegar a 80 metros nos depocentros devido à presença de espessas cunhas de halita. Nessa escala já é possível fazer uma distinção dos tratos de sistemas, embora ainda se note um arranjo cíclico que ocorre em uma escala mesoscópica (dezenas de centímetros).

TRATO DE SISTEMAS DE MAR BAIXO (TSMB): Consiste principalmente de cunhas evaporíticas, formadas por halita e anidritas, que comumente se intercalam com laminitos algálicos e carbonatos de supramaré. Essa associação é indicativa de isolamento da bacia das condições marinhas normais, devido à queda do nível do mar para abaixo da barreira que criou a restrição.

Essas cunhas evaporíticas jazem em onlap aparente sobre carbonatos e anidritas do TSMA, na direção das bordas da bacia (figura 4), onde ocorreu a formação de carbonatos de inter e supramaré, representados por laminitos algálicos associados com siliciclásticos e evaporitos. Nesses locais e nas plataformas carbonáticas da barreira a dolomitização foi intensa. Localmente 
houve aporte de siliciclásticos trazidos pelo vento nos locais onde houve exposição subaérea, associado a feições cársticas (vugs e dissolução de grãos).

\section{TRATO DE SISTEMAS TRANSGRESSIVO (TST):}

A associação litofaciológica mais freqüente inclui folhelhos marinhos, arenitos marinhos de shoreface superior e inferior mostrando muita influência de maré e de ondas, e mudstones/ wackstones laminados e bioturbados.

É neste trato que são encontradas as microfácies mais ricas com relação a conteúdo fossilífero, devido às condições marinhas francas, aeróbicas a disaeróbicas. Nas seqüências mais restritas (S5 e S6), o TST é representado por anidritas que ocorrem sobrepostas às halitas, indicando diluição da salmoura pela entrada de água com menor salinidade na bacia, e por carbonatos laminados ou pelitos laminados, heterolíticos, que provavelmente são seções condensadas, cujo desenvolvimento deve ser maior na direção das bordas da bacia.

\section{TRATO DE SISTEMAS DE MAR ALTO (TSMA):}

O padrão de empilhamento mais característico é o regressivo, identificado pela progradação das seqüências em direção ao depocentro. As superfícies de inundação ocorrem em pelitos laminados pretos, carbonosos, radioativos, e com sulfetos associados, indicando condições redutoras e anóxicas. Nas seqüências mais evaporíticas, a SIM pode se desenvolver como mudstones laminados pretos contendo, por vezes, espículas de esponjas.

Podem ocorrer ainda arenitos com climbing ripples, que indicam a entrada de pequenos lobos de suspensão. A sedimentação do TSMA pode ser encerrada por mudstones intensamente bioturbados e fossilíferos, normalmente os mais afetados por processos diagenéticos, e por anidritas maciças e laminadas subaquosas, que podem ainda exibir a característica textura chicken wire em decorrência de processos diagenéticos.

\section{ANÁLISE CICLOESTRATIGRÁFICA \\ Análise dos Periodogramas:}

SEQÜÊECIA 1: As freqüências melhor representadas (figura 5) indicaram espessuras de $52,3 \mathrm{~m}, 13 \mathrm{~m}$ e 2,4 m, e podem ser relacionadas à excentricidade longa, excentricidade curta $\mathrm{e}$ precessão, respectivamente.

As análises faciológicas feitas nos testemunhos dos poços № 22 e 48 mostraram que as seqüências de 5a Ordem possuem espessuras variáveis entre 2,4 e $5,3 \mathrm{~m}$, o que explica porque essa componente orbital não está tão bem representada no periodograma quanto a excentricidade curta. Além disso, existem intercalações de rochas siliciclásticas que são mais freqüentes em direção à base da seqüência, o que pode introduzir erros nas estimativas.

Ocorrem dez ciclos com espessuras relacionáveis à excentricidade curta, indicando uma duração mínima de 1.000 .000 de anos para a Seqüência 1. A taxa de acumulação situa-se em torno de $163 \mathrm{~m} / \mathrm{Ma}$.

SEQÜÊNCIA 2: As razões mútuas entre as espessuras obtidas (figura 6) não indicam claramente as componentes orbitais, à exceção dos valores de 9,6/11,5 m e $3 \mathrm{~m}$, que podem representar excentricidade curta e precessão, respectivamente.

O valor de 60,2 m não aparenta ter relação com nenhum dos outros, podendo representar uma distorção intrínseca à análise, pois representa metade da espessura total desta seqüência. A espessura de 20,5 m constitui agrupamentos em pares dos ciclos de excentricidade curta.

A partir de dez ciclos de excentricidade curta, a duração da S2 foi estimada em 1.000.000 de anos. A taxa de acumulação total (incluindo camadas de halita) é de $167 \mathrm{~m} / \mathrm{Ma}$, enquanto que a taxa sem halita é muito semelhante à da $\mathrm{S} 1$, de 112 metros.

Tabela 2: Resumo dos resultados obtidos a partir das análises espectrais.

\begin{tabular}{|c|c|c|c|c|c|c|c|}
\hline \multirow[t]{2}{*}{ Sequiência } & \multirow{2}{*}{$\begin{array}{l}\text { Esp. } \\
\text { Total } \\
(m)\end{array}$} & \multirow{2}{*}{$\begin{array}{l}\text { Esp. } \\
\text { s/ Sal } \\
\text { (m) }\end{array}$} & \multirow{2}{*}{$\begin{array}{l}\text { Espes. } \\
\text { Acum. } \\
\text { (m) }\end{array}$} & \multirow{2}{*}{$\begin{array}{c}\text { Duração } \\
\text { (Ma) }\end{array}$} & \multirow{2}{*}{$\begin{array}{c}\text { Duração } \\
\text { Acumulada } \\
\text { (Ma) }\end{array}$} & \multicolumn{2}{|c|}{$\begin{array}{l}\text { Taxa de Acum. Sed. } \\
\qquad(\mathrm{m} / \mathrm{Ma})\end{array}$} \\
\hline & & & & & & Com Halita & Sem Halita \\
\hline 1 & 130 & 130 & 130 & 1,0 & 1,0 & - & 163 \\
\hline 2 & 167 & 112 & 297 & 1,0 & 2,0 & 167 & 112 \\
\hline 3 & 240 & 240 & 537 & 2,0 & 4,0 & - & 120 \\
\hline 4 & 242 & 228 & 779 & 2,0 & 6,0 & - & 121 \\
\hline 5 & 180 & 155 & 959 & 0,9 & 6,9 & 200 & 172 \\
\hline 6 & 130 & 117 & 1.089 & 0,5 & 7,4 & 260 & 234 \\
\hline 7 & 211 & 211 & 1.300 & 1,8 & 9,2 & - & 117 \\
\hline 8 & 185 & 172 & 1.485 & 1,6 & 10,8 & 116 & 107,5 \\
\hline
\end{tabular}


SEQÜÊNCIA 3: O periodograma da S3 (figura 7) mostra uma dispersão de medidas ao redor de determinados valores médios. Isto é resultado dos padrões de empilhamento em thickening e thinning upward presentes na seqüência e já identificados quando da hierarquização estratigráfica.

Ficam, assim, bem evidentes as espessuras de $55,2 \mathrm{~m}$, $11 / 12,8 \mathrm{~m}$ e $3,8 \mathrm{~m}$, que representam excentricidade longa, excentricidade curta e precessão, respectivamente.

A análise estratigráfica indicou a presença de vinte ciclos relacionáveis à excentricidade curta, implicando numa duração de 2.000 .000 de anos, e numa taxa de acumulação de $120 \mathrm{~m} /$ Ma.

SEQÜÊNCIA 4: Os ciclos predominantes (figura 8) são os de $29 \mathrm{~m}, 12,4 / 10,9 \mathrm{~m}$ e com a última freqüência significativa indicando espessura de $2,4 \mathrm{~m}$. É possível relacionar os valores de $12,4 / 10,7 \mathrm{~m}$ e $2,4 \mathrm{~m}$ como sendo excentricidade curta e precessão. A exemplo do observado na S2, o valor de $29 \mathrm{~m}$ parece representar o agrupamento de dois ciclos de excentricidade curta.

Outro modelo possível seria o de considerar $29 \mathrm{~m}$ como excentricidade longa, 12,4 m como obliqüidade e 6/7,9 m como precessão. Entretanto adotar esse modelo implicaria em que a espessura média dos ciclos de excentricidade curta seria o dobro do observado nas seqüências anteriores.

Não parece plausível também que a obliqüidade aparecesse de forma tão acentuada, pois a composição evaporítica da S4 e as reconstituições paleogeográficas para essa época indicam latitudes baixas (entre 20 e $30^{\circ}$ ), onde seu efeito teoricamente seria mínimo. Além disso, o modelo ignoraria uma freqüência muito significativa que é a de $12,6 \mathrm{~m}$.

Assim, é preferível considerar o primeiro modelo. Foram reconhecidos vinte ciclos relacionáveis à excentricidade curta, perfazendo uma duração mínima de 2.000.000 de anos, e uma taxa de acumulação de $121 \mathrm{~m} / \mathrm{Ma}$.

SEQÜÊNCIA 5: As razões entre as espessuras 60,2 m e 17,5 $\mathrm{m}$, obtidos a partir do periodograma da S5 (figura 9), indicam que esses valores se referem à excentricidade longa e excentricidade curta, respectivamente. A componente de precessão não é muito evidente, podendo situar-se entre 4,1 e 7,9 metros.

A análise faciológica e a interpretação dos três testemunhos do poço № 28 (vide figura 10), situado no centro da Sub-bacia do Juruá, mostrou que as seqüências de $5^{\text {a }}$ Ordem se dispõem dentro das seqüências de $4^{\mathrm{a}}$ Ordem segundo um padrão em thinning upward. Assim, a variação constatada de espessuras situouse entre 2,4 e 8,5 metros, o que está compatível com a variação de valores constatada na análise espectral.

A partir desta composição de freqüências pode-se estimar que os nove ciclos interpretados no perfil representam excentricidade curta, indicando uma duração mínima de 900.000 anos para a S5. A taxa de acumulação é de $172 \mathrm{~m} / \mathrm{Ma}$, chegando a $200 \mathrm{~m} / \mathrm{Ma}$ quando as camadas de halita são consideradas. O aumento dessas taxas em relação à S4 indica aceleração da subsidência durante a deposição desta unidade.

SEQÜÊNCIA 6: A interpretação do periodograma da S6 (figura 11) levou em conta que os resultados poderiam estar afetados pelas intrusões de diabásio. Se o diabásio deslocou a halita porventura existente, poderia ter ocorrido a superposição de folhelhos, não permitindo a distinção de ciclos. Nos poços em que não há diabásio nesta seqüência, cinco ciclos foram reconhecidos no perfil. No poço № 68 esses ciclos têm espessura média de $22,4 \mathrm{~m}$, e aparentam serem compostos por outros ciclos de espessura variável entre 10,4 e 12,9 m.

As freqüências entre 2,8 e 4,1 m e possivelmente de $6 \mathrm{~m}$ estão dispostas, a exemplo da S5, segundo padrão thinning upward. A similaridade deste padrão com aquele observado na S5 sugere que esses ciclos podem se relacionar à precessão.

Se isso for verdadeiro, a componente relacionada à excentricidade curta seria de 22,4 metros e a componente de excentricidade longa não estaria evidente pela análise espectral. A duração mínima da S5 poderia ser estimada em 500.000 anos.

Existe também a possibilidade de que as freqüências $55,1 / 12,9 / 2,8-6,0 \mathrm{~m}$ representem excentricidade longa, excentricidade curta e precessão, respectivamente. Se esta hipótese for

Tabela 3: Taxas de subsidência e periodicidades calibradas com dados bioestratigráficos (fusulinídeos) e cronoestratigráficos (87Sr/86Sr).

\begin{tabular}{|c|c|c|c|c|c|}
\hline Andar & $\begin{array}{c}\text { Duração } \\
\text { (Ma) }\end{array}$ & $\begin{array}{c}\text { Espessura } \\
\text { (m) }\end{array}$ & $\begin{array}{l}\text { Taxa } \\
\text { Subsid. } \\
(\mathrm{m} / \mathrm{Ma})\end{array}$ & $\begin{array}{l}N^{0} \text { de } \\
\text { Ciclos }\end{array}$ & $\begin{array}{l}\text { Periodicidade } \\
\text { (anos) }\end{array}$ \\
\hline Neomorrovano & 3,8 & 345 & 90,8 & 25 & 152.000 \\
\hline Atocano & 4,2 & 380 & 90,5 & 33 & 127.273 \\
\hline Desmoinesiano & 4,1 & 572 & 139,5 & 36 & 113.889 \\
\hline Neovirgiliano & & 185 & & 16 & \\
\hline
\end{tabular}


Tabela 4: Periodicidades dos ciclos em algumas sucessões sedimentares pensilvanianas.

\begin{tabular}{|l|l|c|}
\hline \multicolumn{1}{|c|}{ Autor } & \multicolumn{1}{|c|}{ Descrição } & $4^{\text {a }}$ Ordem (ky) \\
\hline O presente trabalho & $\begin{array}{l}\text { Sequiências evaporíticas Pensilvanianas - } \\
\text { Bacia do Solimões }\end{array}$ & $114-472$ \\
\hline Silva (1996) & Megaciclotemas Pensilvanianos da Bacia do Amazonas & $97-340$ \\
\hline Heckel (1986) & Ciclotemas tipo Kansas & $235 / 393$ \\
\hline Hite \& Buckner (1981) & Ciclos bacinais evaporíticos na Bacia de Paradox (EUA) & 110 \\
\hline Goldhammer & Seqüências plataformais carbonáticas da & $230 / 385$ \\
\hline et alii (1994) & Bacia Paradox (EUA) & 390 \\
\hline Ross \& Ross (1987) & Desmoinesiano dos EUA & 400 \\
\hline Algeo \& Wilkinson (1988) & Compilação & $200-500$ \\
\hline Ramsbottom (1979) & Ciclotemas e mesotemas carboníferos da Inglaterra & \\
\hline
\end{tabular}

a correta, haveria 10 ciclos de excentricidade curta, indicando uma duração de 1.000 .000 de anos para a S5.

A decisão entre esses modelos pode ser feita pela comparação com as taxas de outras seqüências com halita. No primeiro caso, a taxa de acumulação seria de $234 \mathrm{~m} / \mathrm{Ma}$ sem considerar as halitas, e de $260 \mathrm{~m} / \mathrm{Ma}$ com halita. No segundo caso, as taxas seriam de 117 e $130 \mathrm{~m} / \mathrm{Ma}$, sem e com halita respectivamente. Em comparação com a S5, o primeiro modelo estaria mais coerente.

Como a análise estratigráfica regional até aqui feita indicou que a deposição da S5 e S6 se deu sob a influência do Evento Tectônico Jandiatuba (Becker, 1997), seria esperado que as taxas de acumulação fossem mais altas devido ao aumento de subsidência, evidenciado pelo Gráfico de Fischer (vide figura 3). Assim, assume-se que a duração mínima da S5 foi de 500.000 anos, com taxas de acumulação com e sem halita de 260 e 234 $\mathrm{m} / \mathrm{Ma}$, respectivamente.

SEQÜÊNCIA 7: A Seqüência 7 exibe uma notável regularidade com relação às espessuras das sequiências, fato bem expresso na figura 12 , na qual a freqüência de 21,1 metros predomina amplamente com relação às demais.

No perfil de raios gama (figura 13), as seqüências de 21,1 metros são assimétricas e nitidamente compostas por duas seqüências de $10 \mathrm{~m}$, sendo que a mais basal é sempre a mais proeminente, enquanto a sequiência superior possui baixa radioatividade e é mais carbonática. Há, também, um agrupamento das sequiências de 21,1 metros em pares (bundling), formando conjuntos maiores da ordem de 45 metros de espessura.

Essas freqüências (43,2/46,4 m, 21,1 m e 10,7 m) foram identificadas no periodograma (figura 12), e representam o caso mais exemplar de ciclicidade composta em todo o Pensilvaniano.

A razão entre os ciclos de 43,2/46,4 m e de 10,7 m sugere que estes representem excentricidade longa e curta, respectivamente. A razão pela qual os ciclos de $10,7 \mathrm{~m}$ se agrupam dois a dois em conjuntos de $21,1 \mathrm{~m}$ não é muito clara.

Considerando a ciclicidade, o padrão assimétrico-regressivo das seqüências, e as relações mútuas entre as freqüências constatadas, interpreta-se que o principal fato modulador da S7 foi a glácio-eustasia. A duração mínima da S7, estimada a partir de 18 ciclos de excentricidade curta, é de 1.800 .000 anos, indicando uma taxa de acumulação sedimentar de $117 \mathrm{~m} / \mathrm{Ma}$.

Tanto a diminuição da taxa de acumulação sedimentar quanto a predominância da glácio-eustasia indicam a diminuição da contribuição relativa da subsidência à geração de espaço deposicional, ao contrário do constatado nas seqüências 5 e 6 . Assim, pode-se considerar que a Bacia do Solimões transformou-se em uma ampla e estável plataforma carbonática durante a deposição da Seqüência 7.

SEQÜÊNCIA 8: A interpretação de ciclicidade na Seqüência 8 deve considerar alguns fatos relevantes. O primeiro é que a idade desta unidade é bem diferente daquela da S7, como indicado pelos dados da curva ${ }^{87} \mathrm{Sr} /{ }^{86} \mathrm{Sr}$, que apontam a existência de um hiato mínimo de $8 \mathrm{Ma}$ entre essas seqüências (figura 14). O segundo é o aparente basculamento da bacia que é evidenciado pela mudança dos depocentros de halita exclusivamente para a Sub-bacia do Juruá já a partir do Atocano (Becker, 1997), e o terceiro é a quase ausência de carbonatos em razão da entrada de siliciclásticos (red-beds) para o centro da bacia.

A mudança de padrão de empilhamento sedimentar com relação à S7 é outro indicativo da provável falta de registro sedimentar na bacia. Com a influência continental mais acentuada, a interpretação baseada em parâmetros orbitais está mais sujeita a erros.

As freqüências identificadas tanto no perfil quanto no periodograma (figura 15) sugerem a presença de ciclicidade. As mais representativas são as de 45,3 m, 21,9/16 m, 9/7,8 m, e 2,8/5,7 m. Entretanto, as relações mútuas são inconsistentes com as da Matriz de Milankovitch para o Pensilvaniano.

Isso pode ter ocorrido por duas razões: ausência de controle cíclico induzido por fatores orbitais; ou pelo fato de não se ter feito descompactação, visto que a proporção de folhelhos e silti- 


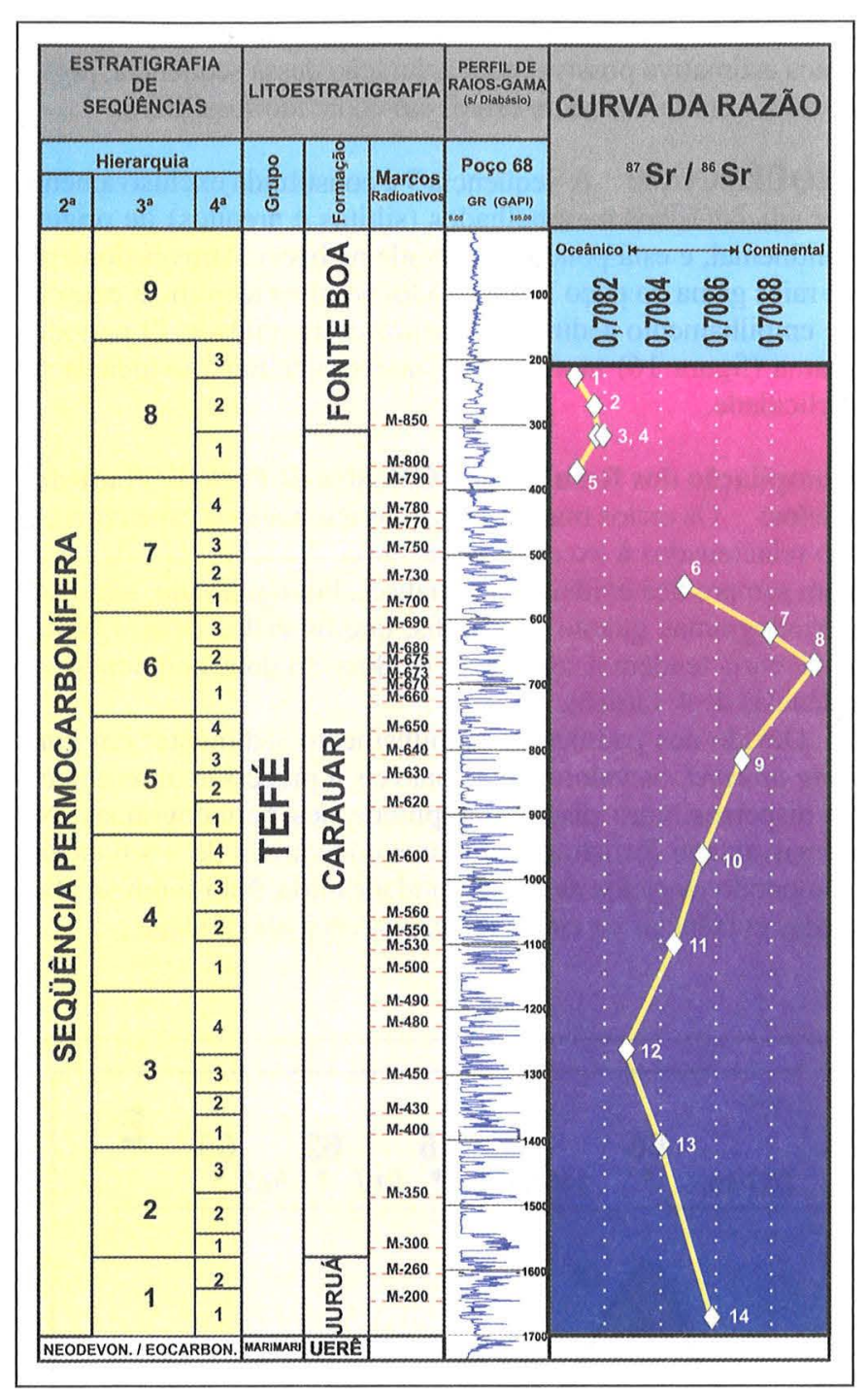

Figura 14: Variação da razão ${ }^{87} \mathrm{Sr} /{ }^{86} \mathrm{Sr}$ ao longo da seção de estudo (Becker, 1997). Notar a grande diferença entre os valores das Seqüências S6 e S7 para a Seqüência S8.

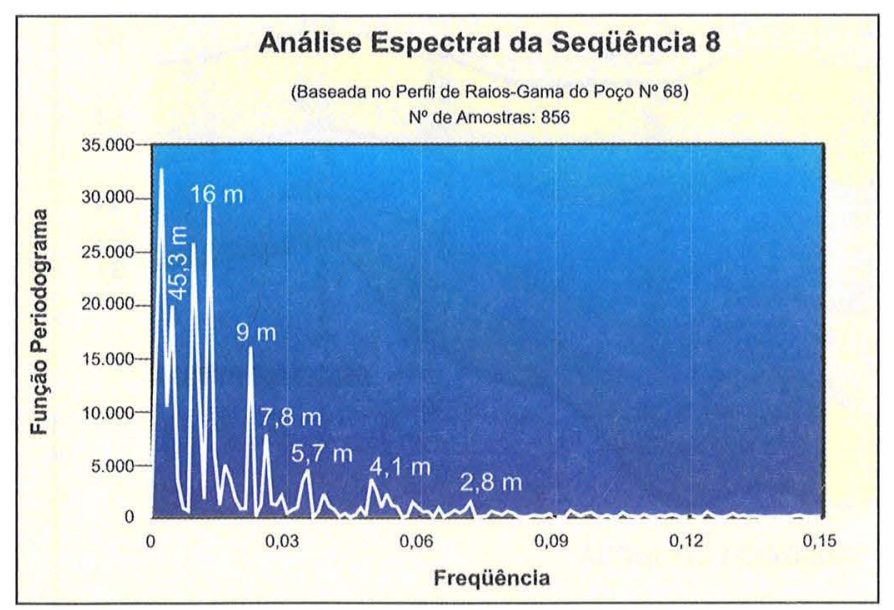

Figura 15: Periodograma da Seqüencia S8.

tos é bem mais alta que nas seqüências anteriores.

Entretanto pode-se fazer uma estimativa assumindo-se que os dezesseis ciclos interpretados na $\mathrm{S} 8$ correspondem às freqüên-

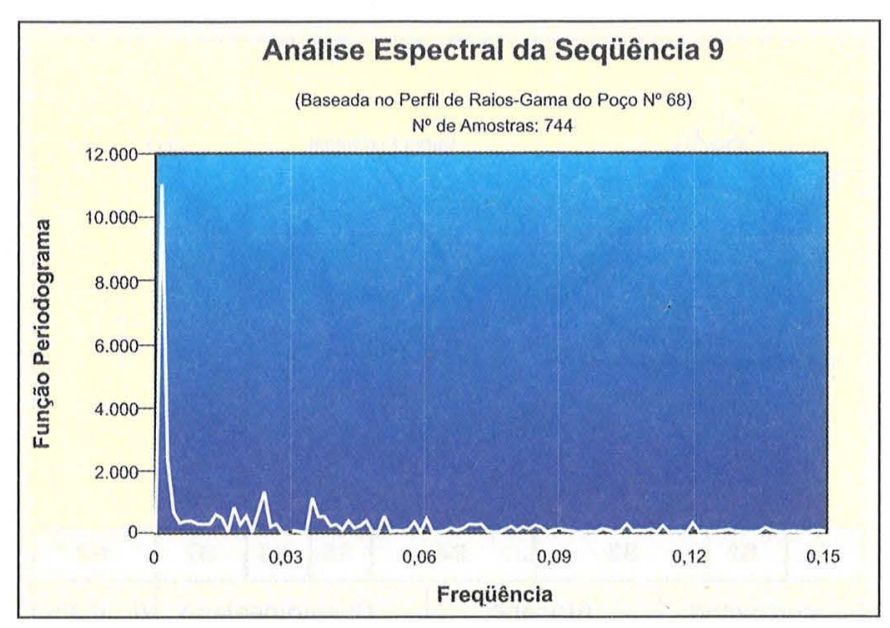

Figura 16: Periodograma da Seqüência S9. Não há nenhuma evidência de ciclicidade.

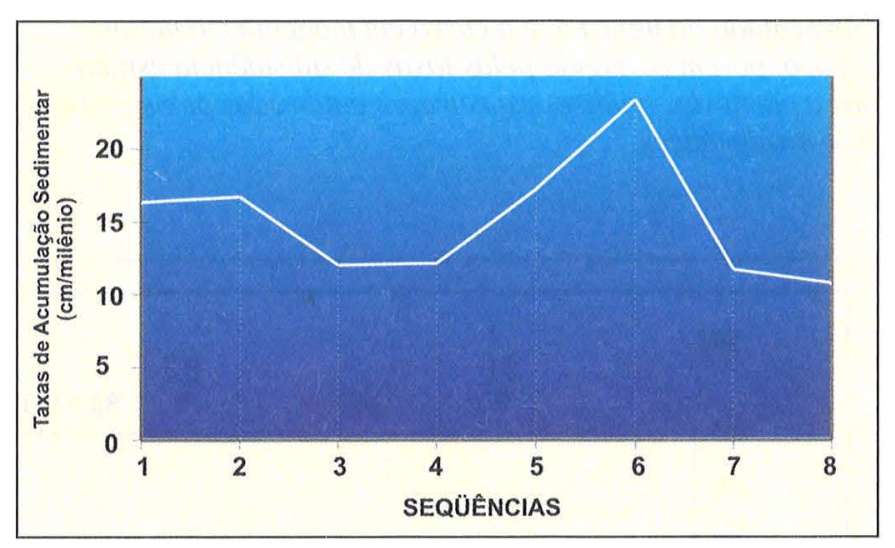

Figura 17: Gráfico ilustrando as variações entre as taxas de acumulação sedimentar obtidas a partir das análises espectrais.

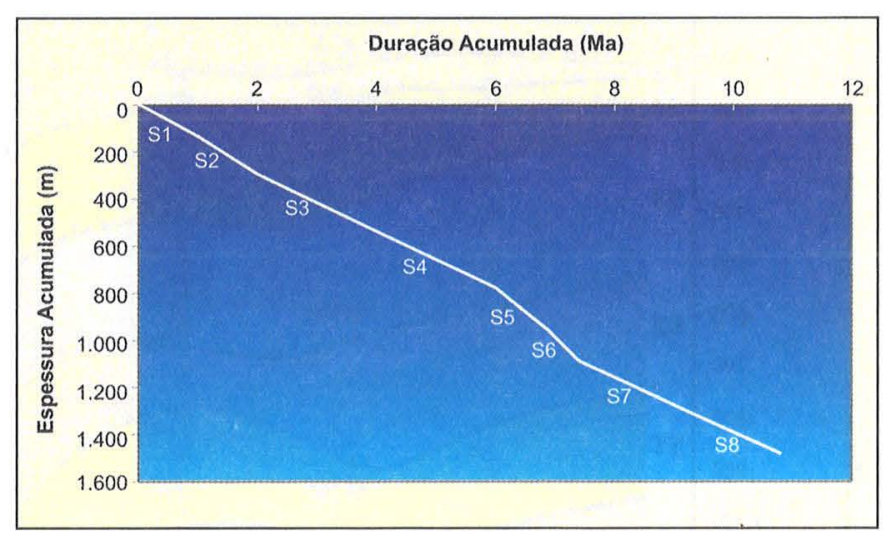

Figura 18: Gráfico de subsidência das seqüências 1 a 8, construido a partir das estimativas de durações feitas com base nos resultados das análises espectrais. Notar aumenio de subsidência nas seqüências 5 e 6.

cias entre 9 e $12,3 \mathrm{~m}$. Nesse caso a relação dessas freqüências com a de 45,3 m seria indicativa de excentricidade longa/excentricidade curta.

Assim, a S8 teria uma duração de 1.600.000 anos, resultando em uma taxa de acumulação de 107 m/Ma que poderia chegar 


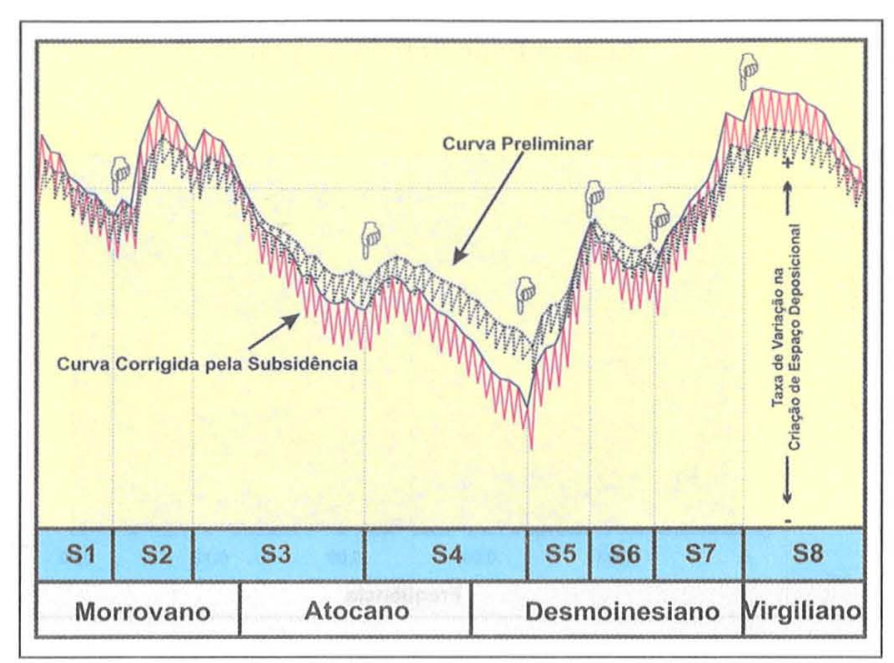

Figura 19: Gráficos de Fischer para o Pensilvaniano da Bacia do Solimões, com indicação dos trechos onde ocorrem as cunhas mais espessas de halita. A curva em preto é o gráfico apresentado na figura 3, e a curva em magenta é o mesmo gráfico, porém corrigido pelas taxas de subsidência estimadas a partir das análises espectrais e calibradas pelos dados bioestratigráficos. a $116 \mathrm{~m} / \mathrm{Ma}$ considerando-se a halita presente na base. Essa é a única estimativa possível para a duração dessa seqüência, pois a mesma é completamente estéril em conteúdo fossilífero.

SEQÜÊNCIA 9: A Seqüência 9 é constituída exclusivamente por siliciclásticos avermelhados (siltitos e arenitos) de origem continental, e está pouco preservada na bacia. Através do perfil de raios gama do poço № 68 não foi possível identificar padrões de empilhamento sedimentar dentro desta unidade. O periodograma (figura 16) também não mostra nenhuma evidência de ciclicidade.

Compilação dos Resultados e Cálculos de Periodicidade dos Ciclos: Os ciclos mais expressivos nas análises espectrais estão relacionados à excentricidade curta. A excentricidade longa nem sempre fica evidente nas análises. Foi observado, tanto nos periodogramas quanto nos perfis, que os ciclos de excentricidade curta tendem a se agrupar de dois em dois, compondo seqüências de $4^{\mathrm{a}}$ Ordem.

Devido aos padrões de empilhamento sedimentar em thinning upward, os valores relacionáveis à precessão apresentamse dispersos, com discreta amplitude nos periodogramas. No Pensilvaniano formaram conjuntos que variam de 3 a 6 ciclos, compondo os ciclos de excentricidade curta. Não foram encontradas evidências de ciclos relacionáveis à obliqüidade.

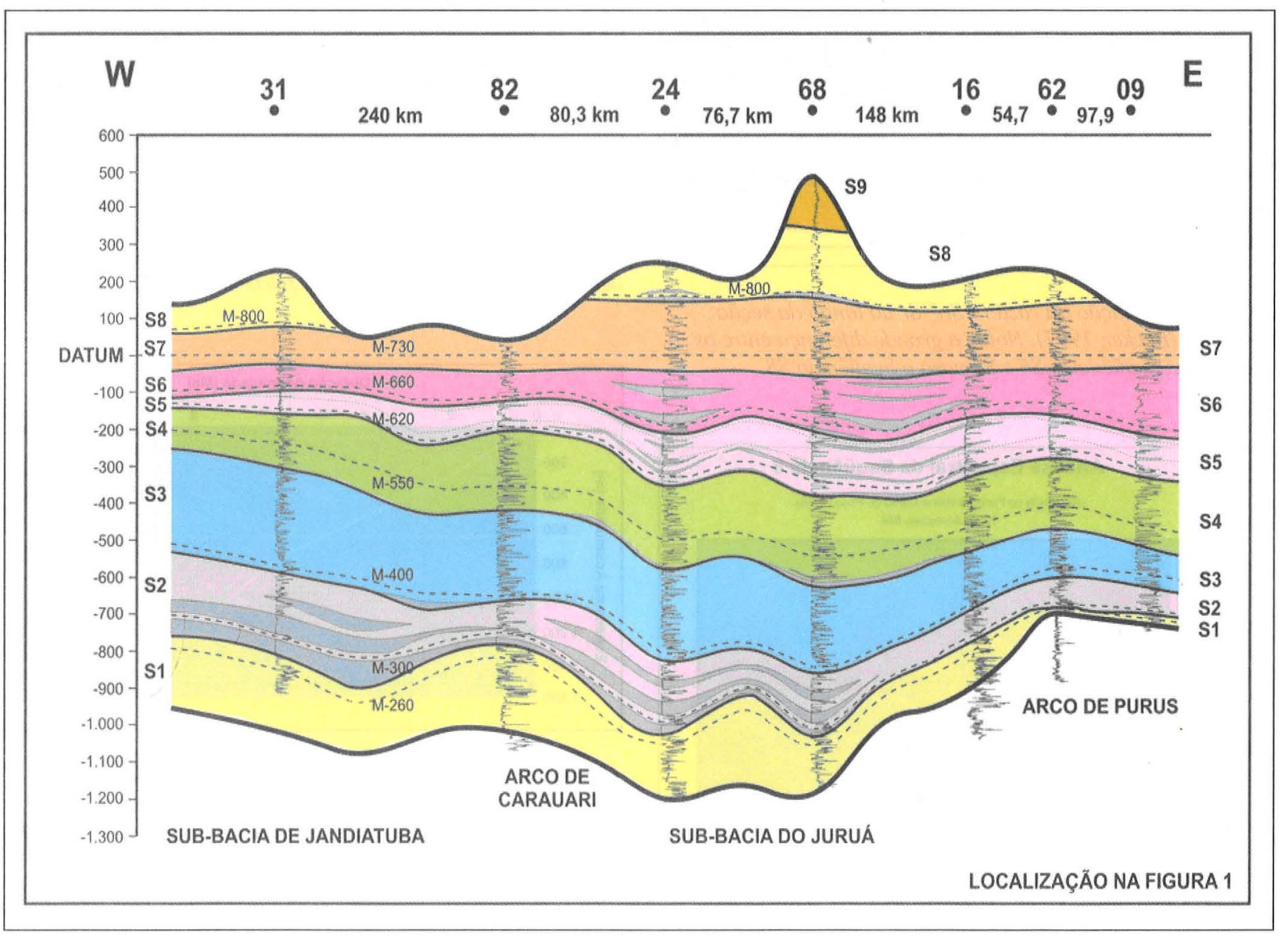

Figura 20: Seção estratigráfica regional Oeste-Este atravessando toda a Bacia do Solimões (Datum: Marco 670). As superficies de inundação máxima de $3^{a}$ Ordem são representadas por folhelhos amplamente distribuídos na bacia, sendo correlacionáveis por centenas de quilômetros até a Bacia do Amazonas. A primeira transgressão marinha que teria ultrapassado o Arco de Purus e invadido a Bacia do Amazonas teria se dado durante o Neo-Morrovano (Marco-260). 


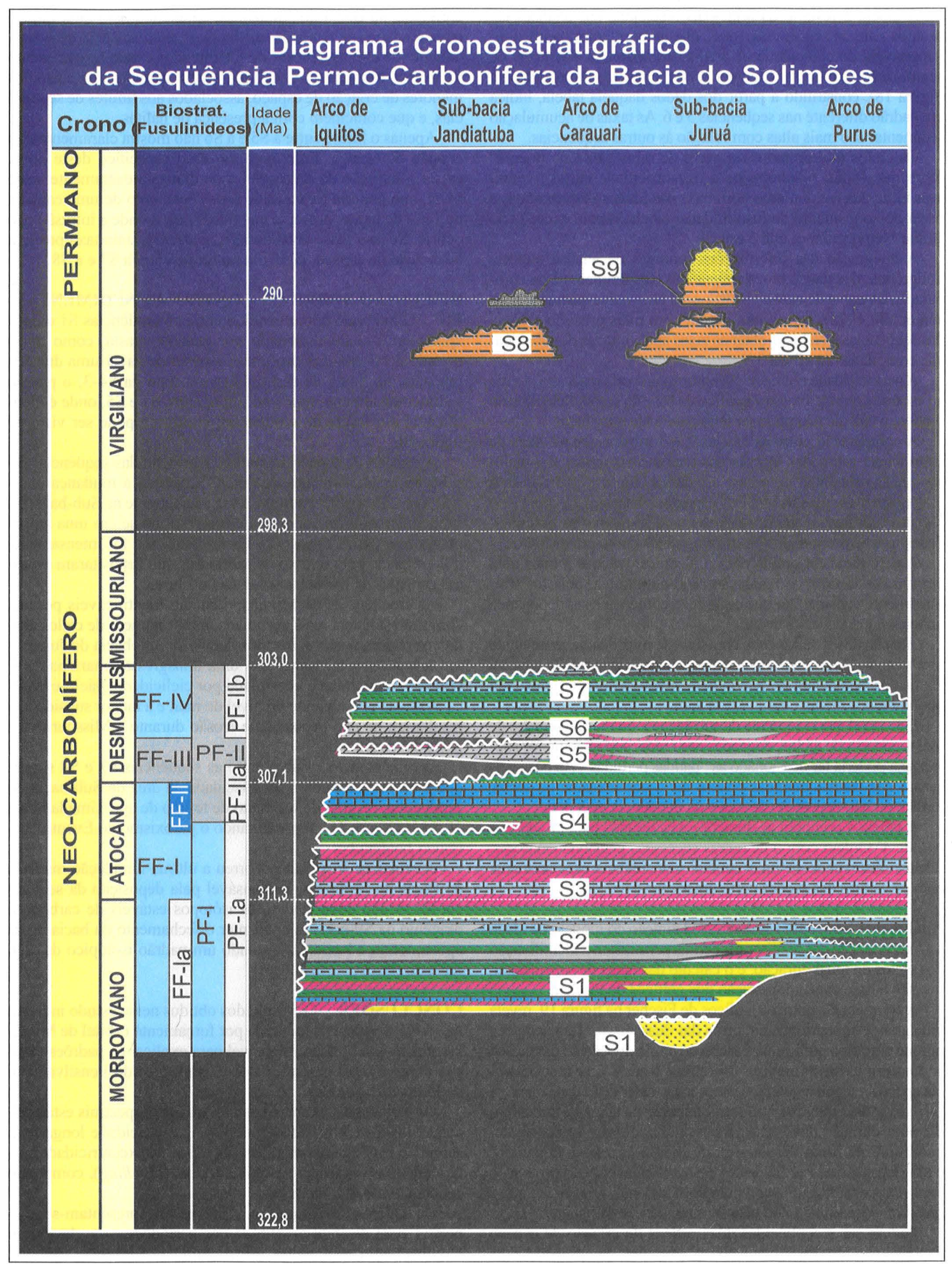

Figura 21: Diagrama cronoestratigráfico baseado na seção estratigráfica regional, nas datações por fusulinídeos e isótopos de estrôncio $\left({ }^{87} \mathrm{Sr}{ }^{\beta 6} \mathrm{Sr}\right)$, e no modelo de idade obtido através da análise cicloestratigráfica. Existe uma discordância regional separando a Formação Carauari da Formação Fonte Boa (red beds). Ocorrem erosões tanto no Arco de Purus quanto no de Carauari. 
A tabela 2 resume os principais resultados das análises espectrais para as seqüências 1 a 8 , que apresentaram padrões interpretáveis de ciclicidade. A análise comparativa das taxas de acumulação sedimentar (figura 17) com o gráfico de subsidência (figura 18), construído a partir dos dados daquela tabela, indica um padrão diferente nas seqüências 5 e 6 . As taxas de acumulação sedimentar são mais altas com relação às outras sequiências.

Os ciclos interpretados no perfil de raios gama do poço $\mathrm{n}^{\circ}$ 68 , e que foram relacionados à excentricidade curta, tiveram suas durações recalculadas com base nas idades determinadas a partir do zoneamento de fusulinídeos (tabela 3) com exceção do Andar Neovirgiliano, que é estéril.

A integração das informações oriundas da análise cicloestratigráfica, dos dados bioestratigráficos (fusulinídeos) e da comparação da curva de razão ${ }^{87} \mathrm{Sr} /{ }^{86} \mathrm{Sr}$ com uma curva-padrão (Denison et alii, 1994), permitiram definir com mais precisão a idade das seqüências e ciclos, e obter as taxas aproximadas de subsidência, compiladas na tabela 3 .

A periodicidade obtida no Neomorrovano está mais alta devido ao escasso controle bioestratigráfico da base da seção. Pelo mesmo motivo, o cálculo não pôde ser feito para o Neovirgiliano.

A comparação entre as tabelas 2 e 3 mostra que as taxas de subsidência estimadas através das análises espectrais são maiores que as calculadas com base em dados bioestratigráficos. Isso já era esperado, pois as análises espectrais baseiam-se apenas no registro sedimentar que ficou preservado, enquanto as periodicidades baseadas em dados bioestratigráficos embutem os hiatos.

A periodicidade obtida para o Neomorrovano é a mais alta, em função da falta de resolução bioestratigráfica, pois foi arbitrariamente considerado que esta seção começou a ser depositada no terço superior deste andar.

A seção de idade Atocano com taxa de subsidência semelhante apresentou valores tendendo à excentricidade curta. Esta tendência fica bastante clara no intervalo de idade Desmoinesiano, cuja periodicidade média é de 114.000 anos.

É possível que o aumento da subsidência favoreça o registro de maior número de ciclos, enquanto nas outras seções a menor subsidência poderia ter ocasionado as "batidas perdidas". As possíveis causas das batidas perdidas podem ser a condensação de seção, erosão, ou não-deposição de ciclos de freqüência mais alta.

A tabela 4 compara as durações encontradas para as seqüências de $4^{\text {a }}$ Ordem com a de outras sucessões pensilvanianas correlatas, observando-se uma notável coincidência especialmente com os valores das seções norte-americanas.

Análise do Gráfico de Fischer A definição do modelo de idade e a interpretação das análises espectrais permitiram a identificação dos ciclos de igual duração, e o cálculo das taxas de subsidência, que são a base para a construção dos gráficos de Fischer.

A comparação entre os gráficos de Fischer na figura 19, revela uma grande similaridadé na forma das duas curvas. Isso acontece porque o gráfico preliminar baseou-se numa divisão de ciclos que se confirmou com as análises espectrais. A correção por subsidência apenas realçou as variações nas taxas de criação de espaço.

Isso indica que, mesmo sem conhecer as taxas de subsidência ou a duração dos ciclos, é possível conhecer a história deposicional na bacia. Bastaria uma divisão criteriosa dos ciclos e usar a espessura média destes como taxa de criação de espaço deposicional (critério usado para confeccionar a figura 3), que é uma boa aproximação da taxa de subsidência da bacia.

Podem ser reconhecidas duas ordens de criação de espaço deposicional no Pensilvaniano. A primeira compreende dois episódios maiores de criação de espaço, ocorridos durante o Morrovano e na passagem Atocano/Desmoinesiano, sendo que este último foi o mais acentuado.

Silva (1996) reconheceu o mesmo evento em sedimentos correlatos na Bacia do Amazonas, apontando para uma importante mudança na fauna de fusulinídeos, marcada pelo desaparecimento de alguns gêneros de fusulinídeos e pelo aparecimento de formas tubulares. A segunda ordem abrange seis episódios menores de criação de espaço, associados aos limites de seqüências, e que coincidem com a presença de halitas.

Apenas o limite entre a S5 e a S6 não mostra claramente esta criação de espaço. Entretanto, no caso específico deste poço, existe a intrusão de uma soleira de diabásio exatamente neste nível, que poderia ter causado o deslocamento de uma camada de $10 \mathrm{~m}$ de halita, presente em outros poços onde a intrusão não ocorre. Se isso fosse considerado, apareceria uma taxa positiva de criação de espaço, tal como no limite entre a S7 e a S8.

\section{DISCUSSÃO SOBRE OS CONTROLES SEDIMENTAR-}

ES O intervalo compreendido entre as seqüências S1 e S4-3 aparentemente foi dominado por glácio-eustasia, como interpretado pelas análises espectrais. Apesar de haver uma drástica mudança na fauna de fusulinídeos no topo da $S 4-3$, o padrão sedimentar somente muda no limite entre S4 e S5, onde é identificável um limite de seqüências, conforme pode ser visto na figura 20.

A criação de espaço durante a deposição das seqüências S5 e S6 foi essencialmente tectônica. É notável a mudança ocorrida na bacia, visível na figura 20 especialmente na Sub-bacia do Jandiatuba, que foi soerguida e transformou-se em uma ampla plataforma carbonática rasa. Essa plataforma foi intensamente dolomitizada pelo refluxo de salmouras que depositaram espessas camadas de halita na Sub-bacia do Juruá.

As frequiências de Milankovitch são identificáveis porque, com a subsidência mais acentuada, maior número de ciclos eustáticos puderam ser registrados dentro da Sub-bacia do Juruá.

A seqüência $S 7$ representa uma transgressão marinha de $3^{\text {a }}$ Ordem, notavelmente controlada por ciclicidade glácio-eustática. A queda subseqüente do nível do mar, e a menor subsidência resultaram na não-deposição e erosão durante o Missouriano e parte do Virgiliano.

$\mathrm{O}$ truncamento erosivo entre as seqüências $\mathrm{S} 7$ e $\mathrm{S} 8$ sugere que a bacia continuou a ser basculada na área da Sub-bacia do Jandiatuba, resultando um hiato de tempo de aproximadamente $10,5 \mathrm{Ma}$ (figura 21), representando o paroxismo do Evento Tectônico Jandiatuba.

Ao final do Virgiliano ocorreu a última inundação marinha da Bacia do Solimões, responsável pela deposição da seqüência S8. A alta covariância dos isótopos estáveis de carbono e oxigênio na $\mathrm{S} 9$ poderia confirmar o fechamento da bacia nessa época, tendo a bacia apresentado um padrão isotópico de lago fechado (Becker, 1997).

CONCLUSÕES Os resultados obtidos nesse estudo indicam que a glácio-eustasia induzida por forçamento orbital de Milankovitch é uma hipótese plausível para explicar os padrões cíclicos observáveis nos carbonatos e evaporitos do Pensilvaniano da Bacia do Solimões.

Os ciclos mais expressivos nas análises espectrais estão relacionados à excentricidade curta. A excentricidade longa nem sempre é evidente nas análises. Os ciclos de excentricidade curta tendem a se agrupar de dois em dois (bundling), compondo seqüências de $4^{\text {a }}$ Ordem.

Os valores relacionados à precessão apresentam-se dispersos, com discreta amplitude nos periodogramas, devido ao empilhamento sedimentar em thinning e thickening upward. Não foi identificado em nenhuma seqüência qualquer ciclo relacionável à obliqüidade.

Importantes mudanças nos padrões de empilhamento sedimentar foram evidenciadas pelo Gráfico de Fischer indicando 
influências tectônicas na criação de espaço deposicional, interagindo com o sinal glácio-eustático.

A convergência entre os valores das periodicidades, calculados a partir de análises espectrais e de dados bioestratigráficos, mostra que a análise cicloestratigráfica é uma ferramenta de grande potencial para estudos estratigráficos de alta resolução no Paleozóico. Mediante um bom controle bioestratigráfico, é possível estabelecer correlações intercontinentais com as seções cíclicas pensilvanianas norte-americanas até a $4^{\mathrm{a}}$ Ordem (na escala dos ciclos de excentricidade curta).

A utilização combinada de várias ferramentas possibilitou a construção de um modelo de idade de alta resolução, e forneceu evidências sobre a causa e a importância relativa dos processos alocíclicos e autocíclicos na construção do registro sedimentar pensilvaniano da Bacia do Solimões.

Agradecimentos São devidos à PETROBRAS S.A. pela oportunidade de desenvolver o projeto de mestrado, e permitir o uso das informações e interpretações aqui veiculadas.

$O$ autor agradece à inestimável orientação do Dr. Peter Szatmari (PETROBRAS/CENPES), que apontou as linhas de trabalho que conduziram este trabalho a bom termo, e ao Dr. Ênio Soliani Júnior (UFRGS/Instituto de Geociências) pelo auxílio na análise e interpretação dos dados de cronoestratigrafia isotópica.

\section{Referências}

Algeo, T. J. \& Wilkinson, B. H., 1988. Periodicity of mesoscale Phanerozoic sedimentary cycles and the role of Milankovitch orbital modulation. Journal of Geology, v. 96, p.313-322.

Altiner, D. \& Savini, R., 1991. Pennsylvanian foraminifera and carbonate microfacies from the Amazon and Solimões Basins: biostratigraphic, paleoecologic and paleogeographic results. Rio de Janeiro, Petrobras/Cenpes, Rel. Interno.

Anders, M. H., Krueger, S. W., Sadler, P. M. 1987. A new look at sedimentation rates and the completeness of the stratigraphic record. Journal of Geology, v. 95, p.1-14.

Azambuja, N. C., Filho, 1990. The Oligo-Miocene Turbidites and Associated Facies of the Campos Basin, Offshore Brazil. Tese de Doutorado (PhD), Imperial College of London, $456 \mathrm{p}$.

Becker, C.R., 1997. Estratigrafia de Sequiencias Aplicada ao Permocarbonífero da Bacia do Solimões, Norte do Brasil. Dissertação de Mestrado em Geociências, Instituto de Geociências, Universidade Federal do Rio Grande do Sul. 363 p.

Becker, C.R.; Soliani Jr, E. \& Rodrigues, R., 1998. Cronoestratigrafia Isotópica do Estrôncio em Evaporitos Pensilvanianos da Bacia do Solimões, Norte do Brasil. In: SBG, XL Congr. Bras. Geol., Anais..., Belo Horizonte, MG, p. 98.

Berger, A.L., Loutre, M.f., Dehant, V. 1989. Pre-Quaternary Milankovitch frequencies. Nature, v. 342, p. 133 .

Berger, A.L., Loutre, M. F. 1994. Astronomical forcing through geological time. In: De Boer, P. L., Smith, D. G. (eds.). Orbital Forcing and Cyclic Sequences. Oxford: Blackwell, IAS, (Special Publication 19). p.15-24

Caputo, M. V., Crowell, J. C. 1985. Migration of glacial centers across Gondwana during Paleozoic Era. Geological Society of America Bulletin, v. 96, p.1020-1036

Crowell, J. C., 1978. Gondwanan glaciation, cyclothems, continental positioning, and climate change. American Journal of Science, v. 278, p.1345-1372.

Eiras, J.F. et alii, 1994. Bacia do Solimões. In: Feijó, F.j. (ed.). Estratigrafia das Bacias Sedimentares do Brasil. Rio de Janeiro, Petrobrás, Boletim de Geociências da Petrobrás, v. 8, n.1, p.17-45.

Fischer, A. G., 1964. The Lofer cyclothems of the Alpine Triassic. Kansas Geological Survey Bulletin, v. 169, p.107-149.

Goldhammer, R. K., Oswald, E. J. \& Dunn, P. A., 1994. High-frequency, glacio-eustatic cyclicity in the Middle Pennsylvanian of the Paradox Basin: an evaluation of the Milankovitch forcing. In: De
Boer, P.l., Smith, D.g. (eds). Orbital Forcing and Cyclic Sequences. Oxford:Blackwell, IAS, (Special Publication 19). p.243-283.

Hite, R. J. \& Buckner, D. H., 1981. Stratigraphic correlations, facies concepts, and cyclicity in Pennsylvanian rocks of the Paradox Basin. In: Wiegand, D. L. (ed.). Geology of the Paradox Basin: Rocky Mountain Association of Geologists-1981 Field Conference, Denver:Rocky Mountain Association of Geologists, p.147-159

Lemos, V. B. 1990. Assembléias de Conodontes do Carbonífero da Bacia do Amazonas. Tese de Doutorado em Geociências, Instituto de Geociências, Universidade Federal do Rio Grande do Sul. 259p.

Mitchum Jr., R.M. \& Van Wagoner, J.c., 1991. High-frequency sequences and their stacking patterns: sequence-stratigraphic evidence of high-frequency eustatic cycles. Sedimentary Geology, Amsterdam, v.70, n. 2/4, p.131-160

Posamentier, H. W. \& James, D. P., 1993. An overview of sequencestratigraphic concepts: uses and abuses. In: Posamentier, H. W., Summerhayes, C. P., Haq, B. U., Allen, G.p. (eds.). Sequence Stratigraphy and Facies Associations. Oxford : Blackwell, IAS, (Special Publication n. 18). p.3-18.

Ramsbottom, W. H. C., 1977. Major cycles of transgression and regression (mesothems) in the Namurian. Proceedings of The Yorkshire Geological Society, v. 41, parte 3-4, p.261-291.

Raup, O. B. \& Hite, R. J., 1992. Lithology of evaporative cycles and cycle boundaries in the upper part of the Paradox Formation of the Hermosa Group of Pennsylvanian age in the Paradox Basin, Utah and Colorado. U.S. Geological Survey Professional Paper, n. 2.000-B, p.bl-b37.

Ross, C. A. \& Ross, J. R. P., 1985. Late Paleozoic sequences are synchronous and worldwide. Geology, v. 13, p.194-197.

Ross, C.A. \& Ross, J.r.p., 1988. Late Paleozoic transgressive-regressive deposition. In: Wilgus, C.k. et alii (eds.). Sea-level Changes: An Integrated Approach. Tulsa:SEPM, (Special Publication 42) p.222-247.

Sadler, P. M.; Osleger, D. A. \& Montañez, I. P., 1993. On the labeling, lenght, and objective basis of the Fischer plots. Journal of Sedimentary Petrology, Tulsa, v. 63, n. 3, p.360-368

Schwarzacher, W. 1991. Milankovitch Cycles and the Measurement of Time. In: Einsele, G., Ricken, W., Seilacher, A. (eds.). Cycles and Events in Stratigraphy. Berlim:Springer-Verlag, p.855-863.

Silva, O.B., 1996. Ciclicidade Sedimentar no Pensilvaniano da Bacia do Amazonas e o Controle dos Ciclos de Sedimentação na Distri- 
buição Estratigráfica dos Conodontes, Fusulinideos e Palinomorfos. Tese de Doutorado em Geociências, Instituto de Geociências, Universidade Federal do Rio Grande do Sul, 331 p.

Soares, P. C., Landim, P. M. B. \& Fulfaro, V. J., 1978. Tectonic cycles and sedimentary sequences in the Brazilian intracratonic basins. Geological Society of America Bulletin, v. 89, p.181-191.

Szatmari, P., Simões, I.a. \& Carvalho, R.s., 1975. Evaporitos da Bacia do Amazonas. Rio de Janeiro, Petrobrás/Depex, Relatório Interno.

Szatmari, P., Carvalho, R.s. \& Simões, I.a. 1979. A comparison of evaporite facies in the late paleozoic Amazon and the middle cretaceous South Atlantic Salt Basins. Economic Geology, v. 74, $\mathrm{n}^{\circ} 2$
- mar/abr, p.432-447.

Veevers, J.J. \& Powell, C. McA., 1987. Late Paleozoic glacial episodes in Gondwanaland reflected in transgressive-regressive depositional sequences in Euramerica: Geological Society of America Bulletin, v. 98 , p. $475-487$.

Youle, J. C., Watney, W. L. \& Lambert, L. L., 1994. Stratal hierarchy and sequence stratigraphy - Middle Pennsylvanian, southwestern Kansas, U.S.A. In: KLEIN, G. D. (ed.). Pangea: Paleoclimate, Tectonics, and Sedimentation During Accretion, Zenith, and Breakup of a Supercontinent. Boulder:GSA, (Geological Society of America Special Paper 288), p.267-285. 